Anuario de Estudios Medievales

41/2, julio-diciembre de 2011

pp. 645-671

ISSN 0066-5061

\title{
EL HIERRO EN LA EDAD MEDIA: DESARROLLO SOCIAL Y TECNOLOGÍA PRODUCTIVA
}

\author{
IRON IN THE MIDDLE AGES: \\ SOCIAL DEVELOPMENT AND PRODUCTION TECHNOLOGY
}

\author{
MARTA SANCHO \\ Universitat de Barcelona
}

Resumen: La utilización generalizada del hierro como material de uso en la Edad Media, puede considerarse como una innovación técnica que tuvo una gran incidencia en el desarrollo de la sociedad medieval. Dicha generalización vino condicionada, en cierta medida, por la introducción, también generalizada, de la energía hidráulica en el proceso de producción siderúrgica, lo que permitió un considerable aumento de la producción y una mejora de la calidad del producto. En este artículo analizaremos los condicionantes sociales que hicieron posible estas innovaciones en la Alta Edad Media, así como la influencia de las mismas en el desarrollo de la sociedad medieval en los siglos siguientes. Estableceremos las distintas fases del proceso de producción de hierro, sus dificultades técnicas y las soluciones que se aplicaron, así como los cambios que percibimos a lo largo de los siglos medievales.

Palabras clave: tecnología medieval; siderurgia medieval; arqueología de la producción.

\begin{abstract}
The widespread use of iron as a working material in the Middle Ages, can be considered a technical innovation that had a strong impact on the development of medieval society. This spread was determined by the introduction, also widespread, of waterpower in the ironmaking process, something that made possible a considerable increase in production and improved product quality. This article explores the social conditions that made such innovations possible in the High Middle Ages, and the influence thereof on the development of medieval society in the following centuries. We shall establish the various stages of iron production, technical difficulties and the solutions that were applied, and the changes that we see throughout the medieval period.
\end{abstract}

Keywords: medieval technology; medieval iron-making; archaeology of production.

\section{SUMARIO}

1. Tecnología medieval y cambio social.- 2. Tecnología y construcción del paisaje.- 3. El hierro en el sistema técnico de la Alta Edad Media.- 4. La terminología: una problemática de difícil solución.- 5. Ubicación, características y evolución de las "fargas" medievales.6. A modo de conclusión.- 7. Bibliografía citada. 


\section{TECNOLOGÍA MEDIEVAL Y CAMBIO SOCIAL}

Este título nos remite a todos a la famosa obra que Lynn White escribió en la década de los 60 del pasado siglo, Medieval Technology and Social Change ${ }^{1}$. A pesar de su concepción algo determinista de la tecnología respecto a la formación de la sociedad medieval, no cabe duda que dicha obra continua siendo un importante referente en todos los estudios que tratan sobre aspectos técnicos de la Edad Media. Por aquel entonces, la economista danesa Ester Boserup, publicó The Conditions of Agricultural Growth en el que planteaba un cambio en la forma de entender el crecimiento demográfico y su relación con la capacidad técnica de una determinada sociedad, oponiéndose de pleno a los posicionamientos malthusianos, por los cuales el crecimiento demográfico viene determinado por cambios anteriores en la productividad agraria, debidos a innovaciones técnicas a menudo consideradas como fortuitas o fruto de la imitación ${ }^{2}$. Según Boserup el proceso de crecimiento debe interpretarse de forma inversa de modo que el aumento demográfico se convierte en la principal causa del desarrollo técnico, en general, y del aumento de la productividad agrícola en particular.

Posteriormente, en su obra Population and Technology Change. A Study in Long-Term Trends, insistirá en este planteamiento y, aunque puede considerarse algo reduccionista, nos invita a entender los procesos de innovación técnica como la respuesta de una determinada sociedad a unas necesidades básicas que en cierta medida, y en el caso de sociedades basadas en el autoabastecimiento, se concretan principalmente en la adquisición de alimentos ${ }^{3}$.

En referencia al cambio técnico, Boserup observa que lo que en general suele considerarse una mejora técnica, como por ejemplo la introducción de determinados aperos de labranza, puede no ser siempre así, dado que en según qué tipo de prácticas agrícolas, la utilización de determinadas herramientas puede llegar a ser incluso contraproducente ${ }^{4}$. Con estas afirmaciones, Boserup pone el acento en la necesaria interdependencia entre las características de los suelos, las formas de uso de la tierra, el utillaje y las prácticas agrícolas más apropiadas para conseguir las producciones que se desea obtener. Para Boserup es un error considerar que la naturaleza posee unos límites de crecimiento que marcan el techo de crecimiento de una sociedad. Las innovaciones técnicas son las que pueden romper ese supuesto techo hasta allí donde sea preciso para el desarrollo de dicha sociedad ${ }^{5}$.

Entendemos, pues, que un determinado colectivo humano, responde a la demanda de alimentos con una intensificación de las prácticas productivas ligadas a un proceso de innovación técnica, ya sea por la introducción de nuevos materiales, nuevas energías, nuevo utillaje o nuevas formas de explotación de los recursos o por la suma de más de una de ellas. De no ser así, la sociedad entra en crisis, se transforma y se inicia un nuevo ciclo.

Ciertamente, la tecnología es un aspecto esencial de la economía de una sociedad. A pesar de ello, los estudios sobre Historia de la Técnica no suelen ocupar

${ }^{1}$ L.T. White, Tecnología.

${ }^{2}$ E. Boserup, Las condiciones.

${ }^{3}$ Idem, Población.

${ }^{4}$ Idem, Las condiciones, p. 40.

${ }^{5}$ J. Mathieu, Ester Boserup, Naturaleza y cultura, pp. 2-3. Este artículo es una muestra de la vigencia de las propuestas de E. Boserup. Sus planteamientos, juntos a los de L. White, constituyen un marco interpretativo y teórico que ha vertebrado numerosos estudios sobre tecnología y sociedad en los últimos 40 años. 
un espacio destacado entre la bibliografía especializada en Historia, por lo menos por lo que respecta a la época medieval. Con ello no quiero decir que no aparezcan referencias a cambios técnicos en obras de marcado carácter socioeconómico. Lo que sucede es que se tiende a simplificar, a extrapolar evidencias de unos lugares a otros, sin prestar demasiada atención a la complejidad del fenómeno y a los múltiples factores que interaccionan en la aplicación de unas determinadas técnicas en un lugar y momento dado. Por otro lado, la costumbre de valorar el nivel técnico de una determinada sociedad a partir de nuestro concepto de progreso, de nuestras necesidades y de aquello que nosotros consideramos positivo, nos ha llevado a emitir unos juicios de valor que poco o nada tienen que ver con la realidad vivida y con el nivel o capacidad técnica de la sociedad analizada.

La posibilidad de establecer comparaciones entre unas sociedades y otras o entre determinados colectivos humanos, pasa, en primer lugar, por saber diferenciar entre los "conocimientos técnicos" y el "nivel técnico". En el primero de los casos nos estamos refiriendo a la esfera del pensamiento, al ámbito teórico que podríamos definir como "aquello que sabemos que se puede hacer pero que nunca o casi nunca hemos realizado". Se trata de un potencial técnico sin desarrollar, aunque puntualmente podemos encontrar evidencias de su aplicación. En todo caso nunca se han generalizado por lo que no han afectado a la mayor parte de la población ni han supuesto cambios significativos en las formas vida, de trabajo y de producción. En el segundo caso, nos encontramos en la esfera de la acción, en el ámbito de lo práctico, que podríamos definir como "aquello que hacemos y aplicamos y que afecta a la mayor parte de la población”. Se trata de una realidad técnica, probada, valorada, contrastada y asimilada, por lo que resulta de aplicación generalizada, afectando las formas de vida, de trabajo y de producción. El paso de la teoría a la práctica, de los conocimientos técnicos al nivel técnico, suele ser lento y sólo se produce si se dan las condiciones necesarias para implementar una determinada innovación técnica. Dichas condiciones suelen ser de carácter diverso, destacando entre ellas, la existencia de agentes activos en la implementación de nuevas tecnologías, la voluntad de satisfacer nuevas necesidades del colectivo y la posibilidad de aplicarlas dentro de un marco socioeconómico determinado.

Precisamente es aquí, al analizar un determinado marco socioeconómico donde encontramos el mayor grado de complejidad. La definición de los grupos sociales y sus funciones, el régimen de propiedad y uso de los recursos naturales (agrícolas, ganaderos, forestales, minerales) y los gravámenes a los que están sometidos, el control sobre las estrategias de producción, el grado y la naturaleza de los intercambios, la tipología de la mano de obra, la existencia de élites y sus características, la ordenación territorial (hábitat, vías de comunicación...), en definitiva, todos aquellos aspectos que intervienen en la definición de un determinado colectivo, desde el punto de vista socioeconómico, interactúan y condicionan la consolidación y desarrollo de un determinado "sistema técnico".

La reflexión entorno dicho concepto, nos ha permitido observar que según a qué distancia situamos el foco del hecho que deseamos analizar, el concepto "sistema

\footnotetext{
${ }^{6}$ Las bases de la definición de este concepto corresponden a B. Gille, Histoire. El mismo autor reconoce la dificultad que entraña precisar que aspectos se deben tener en cuenta para definir un sistema técnico concreto y lo sitúa en el mismo plano que otros sistemas como el económico, el social, el político... con los que interactúa configurando una realidad histórica concreta, cercana a lo que podríamos llamar un sistema global. Existe traducción en castellano de los Prolégómènes en: B. Gille, Introducción. Para el tema que estamos tratando resultan especialmente interesantes las páginas 51-63 de la versión traducida.
} 
técnico" se adapta a la escala y nos permite introducir unos u otros elementos en el análisis. Así pues, en el caso de querer aplicar el concepto a la producción de hierro en un momento histórico concreto, deberíamos escoger aspectos como: la materia prima (características, procedencia y formas de extracción), el combustible (origen y procedencia), las energías motrices (naturaleza e infraestructuras de aplicación), la mano de obra (formación y condiciones de trabajo), el régimen de propiedad o los derechos de uso y explotación de los recursos, los medios de transporte (de materias primas y productos finales), los usos y aplicaciones del producto obtenido...

Definidos estos aspectos, estaremos en condiciones de realizar análisis específicos de realidades distintas, coetáneas o no en el tiempo y lugar. Vemos, pues, como la aplicación del concepto "sistema técnico" nos permite establecer y comparar modelos a partir de la observación de una serie de variables, priorizando aquellas que, a nuestro entender, pueden aportarnos algo de luz a la realidad que nos proponemos analizar.

Por lo que respecta a la producción de hierro, si comparamos el lugar que ocupa esta actividad dentro de los sistemas técnicos tardoantiguo y altomedieval, debemos fijarnos principalmente en dos aspectos. En primer lugar el hierro como material de uso, se generaliza en la Alta Edad Media, substituyendo completamente el uso del bronce, aun considerado el mejor material de uso en época tardoantigua. En segundo lugar la generalización de la energía hidráulica aplicada a diversos procesos productivos, es, también, una de las más importantes innovaciones de la Alta Edad Media. Sin duda alguna destaca su aplicación en la molienda de cereales, de la que disponemos de ejemplos puntuales para época romana como el conjunto molinero de Barbegal, cerca de Arles ${ }^{7}$. A pesar de ello, no cabe duda que la proliferación de estos ingenios se producirá en los primeros siglos medievales.

Las transformaciones que se operan en un ámbito (social, tecnológico económico...) interactúan con los otros generando más cambios lo que nos obliga a romper la cadena por algún eslabón para poder iniciar el discurso. Por nuestra parte, hemos optado por romper la cadena y priorizar lo social, de modo que nuestro punto de partida se centra en los cambios que en este ámbito se desencadenaron en el paso de la Antigüedad Tardía a la Alta Edad Media. Entre estos cambios destacaremos el proceso de ruralización, dispersión y atomización del hábitat que contrasta con el carácter urbano y concentrado propio del mundo antiguo. Este proceso nos es más fácil de entender a partir de la obra de Ch. Wickham, Framing the Early Middle Ages. Europe and Mediterranean, 400-800, en la que realiza un análisis pormenorizado de las transformaciones que se produjeron en el paso de la Antigüiedad a la Edad Media, desde un punto de vista socioeconómico ${ }^{8}$. En las conclusiones admite que ha dejado sin tratar muchos aspectos -entre ellos el técnico, según nuestro parecer-y reconoce que este período resulta extremadamente variable y abigarrado por lo que se hace muy difícil generalizar. Considera que la atomización y dispersión de modelos se hace más acentuada en las zonas montañosas, aspecto que debemos tener en cuenta ya que nuestras investigaciones se han realizado, mayoritariamente, en zonas de estas características.

Otro aspecto a tener en cuenta es el progresivo cierre de las rutas comerciales que hará imposible el abastecimiento de productos procedentes de zonas alejadas. A este hay que añadir la incapacidad de las estructuras de estado para garantizar la protección de la población que se aleja de las ciudades donde la Iglesia ejerce ciertas funciones propias de la administración pública, entre ellas el mantenimiento, en la medida de sus capacidades, del sistema tributario. Así pues, la ruralización de la

\footnotetext{
${ }^{7}$ F. Benoit, L'usine; P. Leveau, The Barbegal; R.H.J. Sellin, The large.

${ }^{8}$ Existe versión en castellano: C. Wickham, Una Historia.
} 
sociedad responde a una necesidad básica de autoabastecimiento, unida a la necesaria autoprotección, lejos del control tributario y sobre territorios en los que no se reconoce propiedad alguna. La existencia de extensiones de terreno donde la escasa población autóctona dispone de unas técnicas bien adaptadas y poco dependientes del modelo romano, ofrece la posibilidad de establecerse e iniciar un nuevo ciclo en el que los conocimientos técnicos procedentes de la tradición romana debidamente adaptados, encontraran un nuevo campo de desarrollo.

Este sería el caso de la utilización de la energía hidráulica que será aplicada progresivamente con más intensidad, en la molinería cerealística, a partir de la versión adaptativamente más adecuada para los regímenes fluviales del clima mediterráneo: rueda motriz horizontal, albercas para la acumulación del agua con pozo de caída, y captaciones de agua simples y fáciles de reparar, o incluso reconstruir, en caso de avenidas torrenciales. La documentación de los siglos IX y X nos permiten observar que la mayor parte de estos molinos fueron, originariamente construidos por comunidades de campesinos y posteriormente fueron absorbidos por las nuevas elites nobiliarias y eclesiásticas.

La ocupación de nuevas tierras, ruptura o aprisión, se entiende en este contexto de reorganización y cambio de modelo, en el que las innovaciones técnicas juegan un papel destacado. Cada acto de ocupación de un nuevo territorio, es un modelo de adaptación al entorno y de organización de la explotación de recursos: más peso de la ganadería y la explotación del bosque, hábitats a media altura, a medio camino entre los pastos, los bosques y las zonas aptas para el cultivo; distribución de cultivos según características y necesidades (cereal, vid, hortalizas) en relación con la calidad de los suelos, su orientación, su proximidad al agua y su acceso; optimización de recursos forestales y minerales, cada tipo de madera y de roca para una utilidad distinta, según sus cualidades físicas y mecánicas (resistividad, flexibilidad, dureza, maleabilidad...); aprovechamiento y gestión del recurso hídrico -ya sea para uso de boca, regadío o energético y provenga de un curso subterráneo, superficial, o de lluvia-, con la construcción de pozos, fuentes, presas y canales, depósitos y cisternas, todo simple pero eficaz y adaptado a las necesidades del grupo que lo crea y construye.

En todo este complejo proceso el agente activo es, sin duda alguna, la clase productora, el campesinado, la mano de obra que, como señalábamos con anterioridad, dispone de un control sobre las estrategias de producción superior al período antiguo. Nada tiene que perder y sólo tiene un objetivo, autoabastecerse y cubrir sus necesidades básicas. Para ello cuenta con zonas donde asentarse, conocimientos técnicos, fuerza de trabajo y la más alta de las motivaciones, su propia continuidad y la mejora de sus condiciones de vida. La cobertura legal que le ofrece la ley antigua a través de la prescripción de los 30 años y una cierta tradición de autogestión de conflictos, propio de colectivos poco romanizados, así como una fuerte cohesión del grupo, les garantizará un mínimo orden y supondrá una progresiva jerarquización de individuos y familias, que conllevará, con el tiempo, la aparición de élites capaces de absorber los excedentes de producción de los que habían sido sus iguales.

Contrariamente a los planteamientos de L. White y E. Boserup, la innovación técnica no determina la forma de organizar la sociedad, como propone el primero, ni mantiene una relación directa con el aumento de la población, como sostiene la segunda. Para que se produzca un cambio técnico, una innovación en el ámbito productivo, se hace necesario que confluyan una serie de variables: la existencia de un grupo cohesionado y activo, que controle las estrategias de producción, con conocimientos técnicos, que disponga de espacio y condiciones para llevarlo a cabo y que tenga una fuerte motivación y capacidad de gestión. Este es el tipo de colectivos humanos que se desarrollaron en el paso de la Antigüedad a la Edad Media, aunque la visibilidad de sus acciones, más que de su existencia, no se producirá hasta que la 
consolidación de las élites sea lo suficientemente sólida como para iniciar un proceso de apropiación de bienes y medios y dejen por escrito su actividad. A partir de ese momento, se iniciará un período de pérdida de protagonismo de aquellos que habían sido los agentes activos del cambio tecnológico, al alejarse, progresivamente, del control sobre las estrategias de producción y perder la motivación inicial que los impulsaba a innovar.

Sociedad medieval y cambio tecnológico, este es el orden en los conceptos que nos parece más adecuado para dar explicación a los procesos de transformación que se suceden en el paso de un sistema técnico a otro.

\section{TECNOLOGÍA Y CONSTRUCCIÓN DEL PAISAJE}

Se entiende por paisaje cultural el resultado de la acción del desarrollo de actividades humanas en un territorio concreto, cuyos componentes identificativos son: El sustrato natural (orografía, suelo, vegetación, agua); la acción humana: modificación y/o alteración de los elementos naturales y construcciones para una finalidad concreta y la actividad desarrollada (componente funcional en relación con la economía, formas de vida, creencias, cultura... $)^{9}$

Esta es la definición de paisaje cultural que podemos encontrar en la página web del Ministerio de Cultura. De ella se desprende la intensa relación existente entre las características de un determinado paisaje y las formas como los colectivos humanos se establecen sobre un territorio en concreto. Los seres humanos tenemos la capacidad de transformar nuestro entorno y ello ya era percibido y valorado como una realidad en la Plena Edad Media. El pensamiento cristiano marca de forma evidente esta forma de entender la relación entre la sociedad y el entorno entendiendo que toda actividad transformadora de la naturaleza debe servir para mejorar y completar la obra de Dios $^{10}$.

Ideologías aparte, resulta evidente el potencial transformador que la actividad humana tiene sobre la naturaleza. Roturar el bosque para crear campos de cultivo, controlar los cursos de agua para dirigirla hacia los molinos, construir edificaciones, extender la red viaria, etc. Si hay que ir al bosque a por leña, se construye un camino; si hay que plantar vid en una ladera, se construyen terrazas; si se quieren cultivar hortalizas se acondicionan espacios y se conduce el agua para el riego. De este modo, y siempre sirviendo a una necesidad previa, se construye un paisaje y para ello se utiliza una herramienta que es la técnica. Dicho de otro modo, entre el binomio naturalezahumanidad existe una relación que se canaliza, se materializa a través de la aplicación de unas determinadas técnicas y según cuales sean estas, el paisaje presentará unas u otras características. En este diálogo, son de vital importancia las características de la propia naturaleza. El clima, el relieve, la vegetación y la fauna, la geomorfología..., condicionaran la existencia de determinados recursos y la forma de explotación de los mismos. De igual manera, las capacidades técnicas de una determinada sociedad,

9 El texto completo puede consultarse en línea: http://www.mcu.es/patrimonio/MC/IPHE/PlanesNac/PlanPaisajesCulturales/Definicion/DefinicionPaisCultural.html.

${ }^{10}$ Sobre este tema resulta muy interesante la lectura de la obra de C.J. Glacken en la que se nos muestran las distintas formas de entender la relación entre el hombre y la naturaleza desde la Antigüedad hasta el siglo XVIII. Para la Edad Media encontramos textos de San Bernardo (1091-1153), San Francisco (1182-1226) o Alain de Lille (1128-1202), Pedro el Venerable (1092-1156) o Santo Tomas de Aquino (1225-1274), entre otros. C.J. Glacken, Huellas, pp. 182-328. 
sus necesidades y su forma de organización, incidirá en las acciones realizadas para explotar dichos recursos. Naturaleza y cultura se entrelazan en una relación sin fin dando lugar a un determinado paisaje.

El estudio de los paisajes culturales históricos, nos permite deducir la aplicación de algunas técnicas productivas, del mismo modo que el conocimiento de ellas nos permite identificar el origen y formación de un paisaje. Así, cuando analizamos las fuentes, podemos recopilar información directa o indirecta sobre actividades productivas y tecnología y relacionar dichas actividades con la construcción del paisaje.

Las fuentes arqueológicas nos aportan evidencias sobre el uso de determinados materiales lo que supone su producción a partir de unas materias primas que son manipuladas a partir de unas capacidades técnicas concretas. Cuando observamos una miniatura en la que nos aparecen una serie de objetos, podemos deducir el tipo de material con el que estaban fabricados y el proceso de producción necesario para su obtención. Del mismo modo, los textos escritos también nos aportan datos sobre objetos y materiales que indirectamente nos informan sobre la capacidad técnica de la sociedad que los creón ${ }^{11}$.

A menudo resulta muy complicado establecer las relaciones existentes entre los recursos las técnicas y el paisaje resultante. Los datos de que disponemos suelen ser dispersos y difícilmente nos informan sobre las técnicas aplicadas o sobre sus consecuencias en la construcción de un determinado paisaje. A pesar de ello, debemos tener en cuenta estos procesos productivos y valorar su capacidad de transformación del entorno.

Actividades extractivas relacionadas con la producción cerámica, la siderurgia o la actividad constructiva, propiciaron profundas transformaciones en el paisaje, con la apertura de trincheras de extracción, el desvió de cursos de agua o el corte de estratos geológicos en los que estaba presente un determinado material. Del mismo modo, la actividad productiva vinculada a la producción de carbón para la siderurgia, propició transformaciones profundas en la distribución y características de los bosques e incluso, combinada con la actividad ganadera, su desaparición a favor de la creación de zonas de pastos ${ }^{12}$.

En determinadas zonas de montaña, la misma ubicación de los lugares de hábitat a una cierta altitud, alejados de los fondos de valle, parece indicarnos un predominio de las actividades productivas vinculadas a la explotación del bosque y a la ganadería, en detrimento de la actividad agrícola, que jugaría un papel secundario dentro de las economías domésticas ${ }^{13}$.

Para el tema de este artículo resulta de vital importancia comprender estas interacciones ya que nos pueden ayudar a entender las razones por las cuales unas determinadas instalaciones se ubican en un lugar y no en otro, dependiendo de las condiciones naturales, las características y el uso que quiera realizarse de un determinado recurso.

\footnotetext{
${ }^{11}$ Recientemente hemos publicado sobre estos temas en: M. Sancho, Aguas; Eadem, Patrones.

${ }^{12}$ Recientemente se están realizando proyectos de investigación de gran alcance sobre la evolución del paisaje en zonas de montaña. Especialmente interesantes son los realizados por el equipo dirigido por J.M. Palet y S. Riera, los cuales están dando sus frutos en forma de tesis doctorales de gran interés para nuestro tema. Como ejemplo véase H. Orengo, Arqueología.

13 J. Bolòs, Els orígens, espec. pp. 151-162.
} 


\section{El HIERRO EN EL SISTEMA TÉCNICO DE LA AlTA EDAD MEDIA}

Como hemos expuesto con anterioridad, en la Alta Edad Media se introducen, de forma generalizada, una energía, la hidráulica, y un material, el hierro. Sobre la energía hidráulica no vamos a hablar ya que en este mismo volumen se publica la interesante aportación de C. Verna. Tan solo señalar que deberemos esperar a la llegada de la máquina de vapor, cuya generalización se efectuará durante el siglo XVIII, para presenciar un cambio significativo en el ámbito de las energías motrices.

En el caso del hierro y el acero, su substitución por otros materiales de uso en aplicaciones como la fabricación de utillaje y armamento o en la construcción, donde se introdujo a partir del siglo XVIII, no se producirá hasta el siglo XX con la generalización del aluminio y la proliferación de aleaciones como el acero inoxidable formado mayoritariamente por hierro con carbono y cromo, hierro en definitiva. La introducción de derivados del petróleo, como los plásticos, no ha supuesto una competencia al hierro ya que son utilizados en campos donde el hierro nunca ha tenido una presencia destacada.

Si aceptamos, pues, que en la Alta Edad Media se generaliza el uso del hierro y de la energía hidráulica, en un proceso lento que arranca en los siglos de transición, debemos descartar cualquier insinuación de retroceso técnico respecto el período antiguo. Quizás sería más adecuado plantearnos un cambio de sistema que, en el campo de la técnica, conlleva un distinto orden de prioridades en las necesidades de los distintos colectivos, unas problemáticas distintas para las que la técnica da unas respuestas diferentes.

Veamos los cambios que se producen en la producción de hierro entre la Antigüedad y la Edad Media.

El modelo antiguo, o mejor aún, el sistema técnico de la antigüedad, daba mayor importancia a las extracciones mineras que al proceso metalúrgico posterior. Ello era debido al mayor interés por la producción de metales no ferrosos. Era necesario destinar una gran cantidad de mano de obra, generalmente esclava, a los trabajos de extracción; construcción de galerías subterráneas y de infraestructuras hidráulicas para la selección y lavado del mineral, sistemas de evacuación del mineral desde las galerías, sistemas de aireación y drenaje... Todo ello requería una organización centralizada y una planificación que permitiera el control de la mano de obra y el mantenimiento del nivel productivo ${ }^{14}$. A pie de mina se instalaban los hornos de reducción y de allí mismo salían, ya, los productos semiacabados listos para el proceso de transformación posterior. La red comercial era la encargada de hacer llegar el producto hasta los centros de consumo y de comercio a larga distancia.

Los centros productores de hierro seguían el mismo modelo y, a menudo, se situaba en la misma zona donde se producían otros metales, para así facilitar el abastecimiento de herramientas que requería el proceso de extracción minera. Su importancia era menor a la de otros metales como el oro, la plata o el cobre. Era considerado un metal complementario, no precioso, poco apreciado dentro de una economía de mercado que precisaba de metales preciosos para la acuñación de moneda y para producir objetos de lujo. Cierto es que ya era utilizado para la fabricación de gran parte del utillaje agrario y del armamento, aunque convivía con el bronce que continuaba

\footnotetext{
${ }^{14}$ Como ejemplo de explotación minera de metales no ferrosos de la Antigüedad, disponemos de la zona extractiva de la Médulas en León: C. Martín, El oro; también disponible en línea: http:// www.sam.mncn.csic.es/senderos\%20II.pdf. Siempre que nos sea posible indicaremos la URL en la que pueden encontrarse los textos citados en las notas con el fin de facilitar su localización por parte del lector.
} 
siendo el metal más apreciado para la fabricación de dichos productos. Esto era así por el escaso conocimiento existente sobre los tratamientos térmicos que permitían endurecer el hierro. Por consiguiente no era un metal muy apreciado ni se consideraba su utilización como una mejora dentro del sistema técnico del momento.

Las investigaciones arqueológicas llevadas a cabo en la zona de la Montagne Noire ${ }^{15}$, Haut-Auxois ${ }^{16}$, Sierra Menera ${ }^{17}$ y en la zona pirenaica del País Vasco ${ }^{18}$, por poner algunos ejemplos, nos aportan información sobre centros siderúrgicos básicamente de cronología antigua. Las baterías de hornos de reducción estaban situadas en las cercanías de las zonas de extracción, evitando, de este modo, el difícil transporte del mineral en bruto. El primer forjado para la extracción de escorias y la compactación de la masa de hierro, se realizaba a mano (forge a bras), un proceso de compactación por martilleo penoso y muy duro de realizar.

Nos preguntamos hasta qué punto la poca capacidad productiva de cada uno de estos pequeños hornos -alrededor de unos $8 \mathrm{Kg}$. por hornada- no estaría condicionada por la dificultad de forjar a mano una masa de tamaño superior o bien si se debería a la complejidad que supone controlar el desarrollo de la hornada misma para la correcta reducción del mineral. Debemos recordar que para reducir los óxidos de hierro, es necesario mantener temperaturas superiores a los $1000^{\circ} \mathrm{C}$ durante horas y asegurar que el carbono, procedente del carbón vegetal, llega a actuar sobre todo el mineral introducido en el horno, propiciando su reducción. A mayor temperatura durante más tiempo, mayor absorción de carbono por parte del mineral y más rentabilidad de la hornada. Suponemos que en hornos pequeños, estas condiciones resultan más fácilmente controlables. La calidad de hierro obtenido dependería de diversos factores: la calidad inicial del mineral, la temperatura máxima obtenida, el tiempo durante el que se mantendría elevada y la efectividad del proceso de primera forja para la correcta expulsión de las escorias y compactación de la masa. Por otro lado, la temperatura en el interior del horno no era homogénea, por lo que la masa de hierro final tampoco lo era. En aquellos puntos donde se había alcanzado mayor temperatura durante más tiempo, el producto final podía llegar a ser hierro acerado, próximo a un acero con poca cantidad de carbono, mientras que en las otras zonas el resultado sería un hierro dulce, sin apenas carbono. Una vez enfriado, la distinta dureza de las partes de la masa indicaría, al técnico metalurgista, la distinta calidad del producto ${ }^{19}$.

Estas apreciaciones de tipo técnico son válidas para todos los procesos siderúrgicos en los que no se consigue fundir el hierro, esto es, en todos los anteriores a la irrupción de los altos hornos. En realidad, el producto más deseado es el hierro acerado o acero (aleación con bajo contenido de carbono) y no el hierro dulce. Las diferencias son claras: el hierro dulce es un material blando, flexible y con capacidad de torsión elevada por lo que no es apto para fabricar objetos cortantes. Por lo contrario, el hierro acerado es un material más duro con el que resulta fácil conseguir un filo.

15 P.M. Decombeix et al., Réflexions, pp. 25-29. [en línea] http://www.persee.fr/web/revues/ home/prescript/article/galia_0016-4119_2000_num_57_1_3207.C. Domergue, Un centre; ídem, Les Martys, con especial interés de las ilustraciones, de la 1 a la 10.

${ }_{16}$ M. Mangin, P. Fluzin, La petite, pp. 141-156.

${ }^{17}$ C. Rico et al., Recherches, pp. 345-353.

18 A. Beyrie, E. Kammenthaler, Aux origines, pp. 28-33; A. Beyrie, E. Kammenthaler, Le centre, pp. 162-164; A. Beyrie, E. Kammenthaler, Inventaire.

19 Según información facilitada por Guillermina Morales, artesana del hierro de la Associació $A F o c$, las pruebas realizadas sobre una masa de hierro reducida en un horno de reducción mediante el sistema directo, permiten diferenciar perfectamente la calidad de las distintas partes de la masa, según se trate de hierro dulce o de hierro acerado. Agradecemos a la Sra. Morales esta información. 
Cierto es que a partir de procesos térmico posteriores, como el temple y el revenido, resulta posible aumentar la dureza de una pieza pero sólo si se parte de un hierro acerado, no de un hierro dulce o puro. Por todo ello podemos decir que el hierro no será un buen material para la fabricación de utillaje y armamento hasta que no se consiga obtener una cierta cantidad de hierro acerado en el mismo proceso de reducción. El hierro dulce se utilizará para fabricar objetos que no precisen un corte vivo, no tengan que soportar fricciones, tensiones o rozaduras de importancia o bien para fabricar piezas que tengan que adaptarse a formas curvadas o retorcidas. También será útil para la fabricación de la parte interior de determinadas armas o herramientas, para dotarlas de flexibilidad y resistencia a la rotura.

En resumen, podemos decir que en la Antigüedad, los hornos de reducción se situaban al pie de las zonas de extracción lo que les daría un carácter itinerante dentro de una zona determinada. La proximidad al mineral y al bosque, de donde se obtenía el carbón necesario, marcaba la ubicación de estos centros siderúrgicos antiguos.

El paisaje se vio alterado por los restos de mineral desechado en la selección previa a la reducción y por los escoriales en los que se acumulan las escorias características del proceso de reducción, formando unos relieves artificiales que pueden ser detectados en las campañas de prospección arqueológica.

Estas características de los centros de reducción de mineral de hierro se mantienen durante siglos mientras no se produce cambio alguno en las necesidades de la población y mientras el abastecimiento de metales es suficiente para cubrirlas. Pero, como hemos señalado con anterioridad, las transformaciones socioeconómicas que se producen en el paso de la Antiguiedad a la Edad Media, conllevan profundos cambios en las necesidades de la población. Ya no llegan los metales básicos -principalmente bronce- procedentes de los centros productores situados en las cercanías de los yacimientos de minerales. Por el contrario aumenta en el conjunto de la sociedad la capacidad de manipular metales, gracias a los conocimientos técnicos metalúrgicos de los elementos germánicos, especialmente por su capacidad de trabajar el hierro en el proceso de forja, a partir de tratamientos térmicos como el temple o el revenido. $\mathrm{Al}$ mismo tiempo, los habitantes de un determinado territorio, conocedores de sus recursos minerales, se ven capacitados para localizar y explotar pequeños afloramientos de óxidos de hierro visibles en superficie. Ante la necesidad de disponer de un material metálico para producir herramientas y armamento y la imposibilidad de conseguirlo a través del mercado, la capacidad técnica del conjunto de la sociedad se pone en marcha y en un momento dado, la documentación se hace eco de esta actividad.

Para los siglos VI, VII y VIII, la información arqueológica y documental es muy escasa. En la mayoría de yacimientos de este período suelen encontrarse pequeños fragmentos de escorias de hierro que indican una cierta actividad siderúrgica de transformación, por lo que debemos suponer que de alguna forma se continuaba produciendo hierro a partir de la reducción de minerales. Investigaciones recientes en Francia, han seguido el rastro de esta actividad y han podido establecer las características principales de la actividad siderúrgica para estos siglos ${ }^{20}$.

Deberemos esperar hasta el siglo IX para empezar a encontrar referencias escritas sobre establecimientos siderúrgicos. Cierto es que, en la documentación consultada para los siglos IX-XIII, la información suele ser muy escasa, tan solo una breve cita de la existencia de una "farga" en un lugar poco definido". Esto es una constante en toda la documentación y a menudo resulta decepcionante la poca preci-

\footnotetext{
${ }^{20}$ G. Pages, La métallurgie.

${ }^{21}$ Normalmente aparecen bajo los términos farga, fabrica fabrega o fabregada. Para más detalles véase M. Sancho, Homes.
} 
sión de los datos existentes. A pesar de ello, podemos extraer algunas conclusiones interesantes.

En primer lugar, podemos destacar el hecho que la documentación utiliza los establecimientos siderúrgicos que llamamos fargas para definir o describir el territorio. Por ello deducimos que se trataba de establecimientos fijos y no itinerantes como era el caso de los hornos de reducción de épocas anteriores. En segundo lugar, la clara relación que se establece en buena parte de la documentación entre los establecimientos siderúrgicos y los cursos de agua. En diversas ocasiones las fargas se sitúan al lado de un río, en otros casos el rió discurre por la farga o aparece como afrontación o límite. A nuestro parecer no hay duda de que las fargas de esta época se situaban cerca de los ríos con la clara finalidad de utilizar su energía. Nos reafirmamos en esta convicción y consideramos que la investigación arqueológica que hemos llevado a cabo tiene un claro valor de prueba al respecto aunque no siempre es aceptada como tal ${ }^{22}$. Según se desprende de la investigación que hemos realizado en la zona del Pirineo catalán, ya en el siglo IX, los hornos de reducción se establecieron cerca de los cursos de agua y se convirtieron en establecimientos siderúrgicos fijos.

Será, pues, la utilización de la energía hidráulica la que marcará este cambio de ubicación que irá ligado a los derechos de uso del agua y a los derechos de ocupación de un determinado espacio. Aunque débiles, las evidencias documentales que indicamos deben ser tenidas en cuenta. Señalaremos tres casos que nos parecen significativos, los tres procedentes del monasterio de Alaón. En el año 851 en "Olibranum in pao Orritense", encontramos una villa cujus nomine Fabrica ... juxta flumine qui vocatur Nocharia, este documento nos indica con claridad la proximidad al río de esta villa llamada "Fabrica". Poco después, en el año 899, otro documento nos informa sobre los límites de un campo utilizando como elemento fijo en el territorio, un establecimiento siderúrgico: et adjacet ipse campus de una latus ad ipsa fabrica qui fuit. Finalmente, ya en el siglo X, en 973, nos encontramos con la cita que para nosotros tiene más relevancia. Se da como afrontación un río que tiene como característica principal que procede de la "Farga": de oriente adfrontat in ipsum rio qui discurrit de ipsa farg $a^{23}$. El verbo "discurrit" lo encontramos también en relación con molinos en otros documentos de la misma época. En 996, por ejemplo, en una venta que Engoncia realiza al abad de Sant Cugat del Vallés, Odón, se presenta la afrontación de poniente con la siguiente expresión: et de occiduo in ipso rego qui discurrit ad ipsos molinos ${ }^{24}$. Ante este documento, nadie dudaría que se trata de unos molinos en el que se utilizaba la energía hidráulica como sí se duda del documento referido a la "farga".

Solamente un cambio tecnológico como la introducción de la energía hidráulica, justifica el traslado de los hornos de reducción a orillas de los ríos, con lo que supone el esfuerzo del transporte del mineral desde las zonas de extracción. Resulta significativa la ausencia de hornos de reducción de los siglos IX en adelante en las zonas de producción siderúrgica del período anterior. En algunas de estas zonas, se han encontrado evidencias de actividad extractiva pero no de reducción siderúrgica ${ }^{25}$,

22 C. Verna considera que las pruebas aportadas en nuestras investigaciones no son suficientes para realizar esta afirmación. Véase C. Verna, Le temps, pp. 78-79; eadem, Réduction, p. 84. En su análisis omite las pruebas documentales presentadas y la metodología aplicada en el proceso de investigación -documentación, prospección y excavación- a través de la cual se identificaron y localizaron más de 80 de estos establecimientos y se excavó uno de ellos. Véase bibliografía en nota 21.

${ }^{23}$ R. d' Abadal, Catalunya, docs. 42, 93 y 220.

${ }^{24}$ J. Rius, Cartulario, doc. 310.

${ }^{25}$ C. Rico et al., Recherches, pp. 345-353. Se habla de evidencias de extracción para el período islámico, sin más precisión, en algunas de las minas localizadas (véase p. 348). 
las cuales, siguiendo nuestros planteamientos, deberían encontrarse cerca de los cursos de agua, quizás debajo de instalaciones de etapas posteriores que, al no haber sido excavadas, esconden los restos de las primitivas fargas de reducción ${ }^{26}$.

En el momento en que realizamos nuestras investigaciones, primera mitad de la década de los 90, los investigadores franceses sostenían la hipótesis que la introducción de la energía hidráulica en la producción siderúrgica había sido obra del Císter y que su difusión iba de la mano de la expansión de esta comunidad monástica, principalmente a partir del siglo XII ${ }^{27}$. Ya en la segunda mitad de la década de los 90, publicamos los resultados en diversos foros, pero fueron ignorados por los autores franceses ${ }^{28}$.

\section{LA TERMINOLOGÍA: UNA PROBLEMÁTICA DE DIFÍCIL SOLUCIÓN}

La interpretación de la terminología que aparece en la documentación medieval relacionada con la industria siderúrgica ha sido objeto de numerosos debates en los que se confrontan dos posiciones opuestas. Los que consideramos que los términos fabrega, fabrica, fabricata, fabregada y farga, con sus correspondientes variantes, hacen referencia a establecimientos dedicados a la reducción de mineral (industria pesada) y los que consideran que todos ellos se refieren a talleres de herrero (industria de transformación $)^{29}$. Probablemente ni unos ni otros estemos en lo cierto y deberíamos ser capaces de buscar explicaciones más matizadas que respondieran a la realidad que estamos intentando analizar.

Esta tarea no resulta sencilla, en primer lugar por la falta de precisión de la misma documentación y en segundo lugar por la más que probable variabilidad del significado de dichos términos a lo largo de los siglos medievales. De hecho el mismo Joan Coromines plantea esta variabilidad y la dificultad que supone definir con precisión dichos conceptos durante el período de formación de la lengua roman$\mathrm{ce}^{30}$. A nuestro parecer, esta dificultad procede de la misma indefinición documental y de nuestra incapacidad para diferenciar cuando se nos está hablando de la industria pesada y cuando de la de transformación, especialmente en la documentación de los siglos IX-XII.

Para dar un paso más en la resolución de este debate, consideramos que debemos analizar la compleja realidad histórica que propició la aparición de estas referencias en la documentación medieval. De hecho, el mismo V. Farías reconoce que es-

\footnotetext{
${ }^{26}$ No podemos olvidar que toda instalación que hace uso del agua como energía, debe disponer de los derechos de uso de la misma, los cuales perduran en el tiempo siempre que el establecimiento se encuentre ubicado en el mismo lugar.

${ }^{27}$ P. Benoit, D. Cailleaux, Moines, 1991. En esta obra podemos encontrar un buen estado de la cuestión en Francia a principios de la década de los 90. Aún en la actualidad los especialistas franceses consideran que la intrioducción de la energía hidráulica al proceso siderúrgico no se producirá hasta el siglo XII, véase G. Pages, La métallurgie, p. 32 y ss.

${ }_{28}$ Únicamente C. Verna cita nuestros trabajos y discute nuestras propuestas, considerando insuficientes las pruebas arqueológicas y haciendo caso omiso de las pruebas documentales (véase nota 22).

${ }^{29}$ V. Farías, Les ferreries. Al inicio de este interesante artículo, se hace referencia a la evolución de los términos fàbrega y farga, derivados del latín fabrica, y a la dificultad de diferenciar su significado al inicio de la aparición del catalán, más por factores geográficos y semánticos que por simples distinciones fonéticas. Por nuestra parte, la primera cita documental en la que hemos localizado el término "fabrica" es del año 851, "fabrigada" aparece por primera vez en 955 y "farga" en el año 973. Véase R. d'Abadal, Catalunya, docs. 42, 166 y 220.

${ }^{30}$ J. Coromines, Diccionari, vol. III, p. 839.
} 
tas palabras possiblement, designaven en un principi tant la ferreria pròpiament dita com el lloc on es realitzava el tractament inicial del mineral per extreure'n el ferro. Estamos completamente de acuerdo con esta afirmación y aún más, estamos convencidos que todos los establecimientos dedicados a la reducción de mineral, disponían de un taller de herrero que daba servicio a los habitantes de la zona y que era, sin lugar a dudas, la parte más visible, percibida por sus usuarios como un servicio indispensable. Por el contrario, la parte destinada a la reducción del mineral no revestía ningún interés, ni para los usuarios ni para los poderes feudales que controlaban las instalaciones. El modelo feudal establece, principalmente, un control de la producción en la fase final del proceso de producción, tal y como sucede en otros procesos productivos como el agrícola o el ganadero, e impone un censo sobre el uso final que en este caso se materializa en la acción de reparar o adquirir herramientas (llòsol en catalán).

La misma confusión la encontramos en la denominación de los artesanos que se dedicaban al trabajo del hierro. En la documentación, a menudo en el mismo documento, nos aparecen como faber y ferrari sin que sea posible discernir hasta qué punto son utilizados como sinónimos o si se refieren a la doble tarea de reducir minerales y de reparar y fabricar herramientas ${ }^{31}$. Incluso al referirse al servicio que prestan estas instalaciones aparece la confusión ${ }^{32}$.

Quizás la clave para entender esta situación esté en comprender la evolución histórica y técnica, el proceso que llevó a la especialización en la Baja Edad Media y que no encontramos, con la misma intensidad en la Alta y la Plena Edad Media. Nos ayudará a entender este proceso profundizar en la obtención de las materias primas. El herrero necesita materias primas, fundamentalmente hierro, y este no procede de las minas, tal y como se ha afirmado en alguna ocasión ${ }^{33}$, ya que de ellas se obtenía el mineral en bruto que luego había que reducir. En nuestra propuesta interpretativa consideramos que dicho metal se obtiene, en una primera fase, sobre el terreno, explotando el mineral que se encuentra en superficie y realizando la reducción en unos establecimientos que, en muchas ocasiones, pueden coincidir con el lugar donde encontramos talleres de herrero. Ello no impide que proliferen estos talleres en otros lugares sin coincidencia con la industria pesada como bien está demostrando la arqueología en los últimos años.

Recientemente, en el ámbito catalán, la arqueología ha venido a corroborar esta interpretación con la identificación de diversos talleres de este tipo ubicados en distintos entornos rurales y protourbanos: En hábitats vinculados a una comunidad monástica como el de Monistrol de Gaià (Bàges) fechado por radiocarbono entre los siglo $\mathrm{X}-\mathrm{XI}^{34}$ y el de Sant Pere de Graudescales (Solsonès) fechado a mediados del siglo $\mathrm{XI}^{35}$; en lugares especialmente humildes o poco destacables desde el punto de vista poblacional como es el caso de "El Coll de les Caixes" (Bàges), con una data-

\footnotetext{
${ }^{31}$ V. Farías, Les ferreries, doc. 5, p. 51. En este documento de 1205 aparece un personaje citado de las dos manera, "Geraldum, ferrarium de Palacio" y "Geraldus, faber". La documentación nos ofrece otros ejemplos como el personaje que nos aparece en el año 1258 vinculado al monasterio de Santa Maria de Gerri y que es definido como "ferrario sive fabro". Véase I. Puig, El Monestir, doc. 255; M. Sancho, Homes, doc. 109, pp. 272-273 y doc. 132, pp. 286-287.

${ }_{32}$ V. Farías, Les ferreries, doc. 6, p. 52, donde al referirse al servicio que debe prestar la "fabricam de Apierola" indica "servicium fabrice et ferrarii" lo que, creemos, hace referencia a dos actividades claramente diferenciadas.

${ }^{33}$ V. Farías, Les ferreries, pp. 38-39.

34 J. Gibert, L'Alta Edat Mitjana, pp. 526-529.

35 J.I. Padilla, Aportación, pp. 197-224.
} 
ción absoluta dentro del siglo $\mathrm{XI}^{36}$; en hábitats en altura como los de Coma Peronella (Cerdaña francesa), con una datación por radiocarbono correspondiente a los siglo VII-VIII y el yacimiento andorrano de El Roc d'Enclar con una datación similar al anterior $^{37}$; en hábitats concentrados como el localizado en el yacimiento de L'Esquerda (Osona), fechado en los siglos XII-XIII ${ }^{38}$; en centros de hábitat concentrado con vocación urbana como serían los casos de Perelada (Alt Empordà), fechado a mediados del siglo XI y Olèrdola (Alt Penedès) sin que se disponga aún de una datación precisa pero que podemos situar en la Plena Edad Media ${ }^{39}$; en el interior de iglesias como es el caso de Sant Joan del Pla (Baix Llobregat), fechado en el siglo XI ${ }^{40}$; en las cercanías de castillos como serían los casos hallados en el Barrio del Castillo de Mataplana (Ripollès) y el del Castillo de Montsoriu (La Selva), ambos con una cronología similar correspondiente a los siglos XIII-XIV ${ }^{41}$.

Otro argumento que debemos tener en cuenta está relacionado con otra materia prima, el carbón. Su aparición en la documentación en relación con la actividad siderúrgica es clara y los estudios realizados sobre muestras de polen y otros indicadores paleoambientales así lo demuestran ${ }^{42}$. No cabe duda que, a lo largo de la Edad Media los usos del bosque se encuentran cada vez más controlados debido a la gran cantidad de materiales que aportan y que van destinados a actividades productivas y constructivas muy diversas. No es de extrañar, pues, este interés que se refleja en la documentación. Pero debemos tener en cuenta que para realizar tareas de reparación y fabricación de utillaje, no resulta imprescindible el uso del carbón, es suficiente

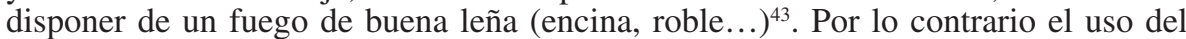
carbón es imprescindible en el proceso de reducción. Así pues, cuando Bernardo Ferrario se compromete en 1190 a realizar las obras necesarias para el mantenimiento de los molinos reales del Llobregat cum ferro meo et carbone, deberíamos preguntarnos a qué se está refiriendo. ¿No será el hierro que él mismo ha producido a partir de la reducción de mineral, con el carbón correspondiente? ${ }^{44}$.

La documentación medieval, generada normalmente por los grupos de poder que controlan el sistema, suele ser rica en información sobre las actividades grabadas por algún tipo de censo, como es el caso del uso de los servicios de los herreros u otros monopolios como los molinos o los hornos de pan. Por lo contrario, no se prodiga en ofrecernos información sobre aquellas actividades o medios de producción que no generan rentas. Del mismo modo que casi no encontramos datos sobre los hornos de cerámica o de cal, tampoco nos hablan de la fase de reducción del hierro. Por esta razón, querer aproximarse a la realidad del proceso de producción de hierro en la Edad Media sin con-

\footnotetext{
36 J. Gibert, L'Alta Edat Mitjana, pp. 530-561. 365.

${ }^{37}$ P. Campmajó et al., Un atelier, pp. 133-167; M.C. Rovira, J. Solans, Les activitats, pp. 351-

${ }^{38}$ O. Amblas, J. Molera, I. Ollich, Estudio, pp. 500-509.

39 J. Llinàs et al., Excavacions, pp. 147-155; J.M. Bosch et al., Olèrdola, pp. 95-99.

40 J.M. Vila, Excavació, pp. 536-544.

${ }^{41}$ X. Raurich, A. Mestre, L'excavació; J. Tura, O. Amblas, El material, pp. 58-65.

42 S. Riera, A. Esteban, Vegetation, pp. 7-23; C. Dubois, J.P. Metailie, V. Izard, Archéologie, pp. 525-540.

${ }^{43}$ En ninguno de los casos en que la arqueología ha dado con talleres de herrero se ha podido constatar la presencia de depósitos de carbón para el funcionamiento del fuego del taller. Por lo contrario el combustible utilizado parece corresponder a leña de buenas maderas tales como encina o roble. El uso de carbón habría generado algún nivel arqueológico de coloración gris-negra y de una potencia considerable, tal y como apareció en los niveles de circulación de Fabregada.

${ }^{4}$ V. Farías, Les ferreries, doc. 4, p. 50; M. Sancho, Homes, doc. 104, pp. 268-269.
} 
tar con los datos que nos ofrece la arqueología, resulta imposible ${ }^{45}$. Por ello defendemos y reiteramos nuestras propuestas que, siguiendo estos planteamientos, nos han permitido localizar y excavar la farga de Fabregada, la cual aparece en la documentación con los término illa farga, en 1010 y ipsa fabricata en 1038 y que, sin duda alguna corresponde a un establecimiento dedicado a la reducción de mineral de hierro ${ }^{46}$.

Los talleres de herrero, corresponden a la industria de transformación, no a la industria pesada como sí lo son los centros de reducción. Sus instalaciones son muy simples: un fuego, parecido a un hogar a ras de suelo o elevado para facilitar la manipulación (fornal en catalán), con o sin un pequeño fuelle para avivar el fuego, un soporte o yunque para martillear la pieza y un pequeño depósito de agua o recipiente móvil para realizar los tratamientos térmicos necesarios. Pero cuando hablamos de fargas nos referimos a instalaciones algo más complejas y con mucho más impacto en el territorio, lo que justificaría su utilización como puntos de referencia en el espacio. Debemos añadir, además, que en el clima mediterráneo, marcado por las lluvias torrenciales y el desbordamiento de ríos y arroyos, nadie situaría un centro de producción al lado de una corriente de agua tan solo para llenar un cubo. Únicamente en el caso de tener que emplear el agua como energía se procedería de tal manera y este es el caso de los molinos harineros, los batanes, los molinos papeleros y las fargas.

\section{UBICACIÓN, CARACTERÍSTICAS Y EVOLUCIÓN DE LAS “FARGAS” MEDIEVALES}

Las fargas de los siglos IX al XI se encuentran situadas en las mismas zonas donde se está desarrollando un proceso de ocupación del suelo agrícola y un aumento de la actividad ganadera, donde el hierro resulta un producto de primera necesidad. Dichas zonas no suelen disponer de grandes yacimientos de mineral apto para reducir, pero sí disponen de afloramientos de pequeñas aglomeraciones de óxidos de hierro depositadas en cavidades kársticas por la acción del agua, fáciles de extraer y de una calidad excelente $^{47}$. A menudo estos depósitos de minerales no figuran en los estudios geológicos habituales por ser insignificantes. Afortunadamente disponemos, para Cataluña, de un estudio pormenorizado, municipio a municipio, en el que se relacionan los más insignificantes depósitos de mineral ${ }^{48}$. A partir de dicho estudio, hemos podido constatar como todas y cada una de las fargas documentadas para el período indicado, se encuentran en las cercanías (entre 0 y 8 quilómetros) de dichos yacimientos de óxidos de hierro ${ }^{49}$. Estas condiciones se pudieron mantener mientras la producción iba destinada al au-

\footnotetext{
${ }^{45}$ Recientemente se ha publicado un volumen que recoge diversos estudios realizados a cerca de la actividad minera y metalúrgica en Al-Andalus. Algunas de las aportaciones hacen referencia a la producción de hierro y ponen de relieve la necesidad de relacionar los lugares de hábitat, las características medioambientales y la actividad metalúrgica. Así mismo señalan las dificultades de llevar a cabo este tipo de investigaciones y la necesidad de planificar proyectos de investigación interdisciplinarios con la participación de documentalistas, arqueólogos, geólogos, ambientalistas, analistas, etc. A. Canto, P. Cressier, Minas.

${ }^{46}$ Sobre este yacimiento se ha publicado una monografía en versión bilingüe (catalán/castellano), véase M. Sancho, Ipsa Fabricata, y nuestra tesis doctoral: eadem, Homes.

${ }^{47}$ Esto es lo que se desprende de los análisis metalográficos realizados por Júlia Simón, de la Universitat Politècnica de Catalunya, sobre los materiales procedentes de la intervención arqueológica en el yacimiento de "Fabregada". Véase J. Simon, Testimonios, pp. 107-129.

${ }^{48}$ Para consultar estos datos véase J.M. Mata, Els minerals.

${ }^{49}$ Para observar la ubicación de los yacimientos de óxidos de hierro respecto las fargas documentadas, véase la cartografía publicada en M. Sancho, Homes.
} 
toabastecimiento dentro de un ámbito territorial reducido, que podemos definir como demarcaciones de tamaño medio ${ }^{50}$. Tampoco estaban demasiado lejos de bosques capaces de producir el carbón necesario para realizar el proceso de reducción del mineral. Un carbón que, en el caso catalán, procedía principalmente de encinas y robles, y que era transportado hasta las instalaciones de reducción en grandes cantidades del mismo modo que lo sería el mineral, previamente seleccionado. Sólo la utilización del agua como energía justifica el esfuerzo que supone el transporte de estas materias primas imprescindibles para el proceso de reducción, ya que, de no ser así, los hornos continuarían ubicándose lo más cercanos posible a las zonas de extracción y a los bosques.

La presencia de estas instalaciones supone nuevos cambios en el paisaje relacionados con la domesticación de los cursos de agua, la aparición de escoriales en lugares próximos a la fargas o el acondicionamiento de nuevas vías de comunicación entre las zonas de extracción, los bosques y los establecimientos siderúrgicos.

Podemos describir cómo serían estas instalaciones a partir de la excavación que realizamos en Fabregada. El elemento central sería el horno, generalmente excavado en el estrato geológico, revestido con arcilla por el interior (figura 1). A media altura de la cámara de reducción se hallaría la entrada del canal de aire forzado procedente del exterior. Su entrada presenta una inclinación de unos $45^{\circ}$ y en el otro extremo de dicho canal de aire se encontrarían los fuelles accionados manualmente y de forma alternativa para insuflar un caudal de aire lo más continuo posible (figuras 2 y 3). En el centro de la cámara de reducción se iniciaba el canal de evacuación de escorias las cuales salían del horno para depositarse en una pequeña cavidad o pozo de escorias situado en la parte delantera del horno. Las escorias, una vez enfriadas, eran llevadas al escorial situado en las proximidades, pero nunca sobre la corriente de agua cercana para no taponar su curso. La apariencia de estas escorias es muy característica. Por la parte inferior reflejan la superficie sobre la que se han depositado, generalmente algo rugosa debido a la escorificación del fono del pozo. La más grande hallada en la excavación de Fabregada, tenía un espesor de unos 10 centímetros y estaba formada por distintas capas de colada, formando en la parte superior de la misma unos cordones escorificados propios de este tipo de proceso (figura 4). Su elevado peso revela un proceso de reducción poco desarrollado ya que buena parte del hierro se escurría con la escoria y no era aprovechado en el proceso ${ }^{51}$.

A un nivel algo más bajo que el horno, se encontraría la zona destinada a la primera forja, ocupada por un pequeño martillo hidráulico del que se localizaron, en Fabregada, los encajes excavados en el suelo geológico y el punto de entrada del árbol de levas que sería accionado por una pequeña rueda motriz situada en el exterior del edificio, sobre el cauce del arroyo. Dicho arroyo presenta una sedimentación en horizontal que define un microrelieve correspondiente a la colmatación de la presa, probablemente de madera, que servía para almacenar el agua destinada a accionar el mazo. A pesar del escaso material hallado en la excavación de este establecimiento, tuvimos la fortuna de localizar dos fragmentos cerámicos en la trinchera de cimentación del muro donde se encuentra la entrada del eje motriz, las cuales responden a tipologías características de finales del s. X o principios del s.XI, y que coincidiría con las primeras citas documentales en 1010 i $1038^{52}$ (figuras 5 y 6).

50 Sobre las demarcaciones territoriales y sus dimensiones resulta interesante el estudio realizado por J. Bolòs, Els orígens, p. 152 y ss., donde podemos encontrar información sobre las distancias que suelen separar los hábitats de los recursos.

51 Véase nota 46.

${ }^{52}$ En el año 1010 encontramos la cita de la iglesia de Sant Esteve en el lugar llamado "illa farga" que R. d'Abadal identifica con Sant Esteve de la Sarga. R. d'Abadal, Catalunya, p. 30. Posterior- 
A un nivel algo superior al horno se encuentra la zona de almacenamiento del mineral de hierro, donde pudimos recuperar muestras de óxidos de hierro, principalmente goethita y limonita, de apariencia terrosa y de una calidad excelente para un proceso de reducción con la tecnología descrita ${ }^{53}$.

Resulta interesante señalar la diferente coloración de los niveles de circulación de las distintas terrazas que ordenan el interior de la farga. Mientras las partes altas, afectadas por el depósito de mineral y la parte superior del horno presentaban colores anaranjados y rojizos, la parte baja, cercana a la salida del horno, al pozo de escorias y al mazo tenía un color negro-grisáceo de apariencia ceniza, sin duda por la influencia de las acciones de vaciado del horno y del almacenamiento del carbón ${ }^{54}$.

Los datos recogidos durante las campañas arqueológicas y la interpretación que de ellos hemos llevado a cabo, nos han permitido realizar una reconstrucción ideal de este establecimiento en la que se puede observar la distribución del espacio interior y el sistema hidráulico del que estaría dotado (figura 7).

No disponemos de datos arqueológicos que nos permitan aproximar el abandono del establecimiento siderúrgico, aunque si podemos afirmar que el poblado asociado a la farga fue abandonado durante el primer cuarto del siglo XIV.

Por lo que respecta a los derechos de explotación y propiedad de las fargas, y en las escasas ocasiones en las que la documentación nos habla explícitamente de ellas, constatamos un cambio en la propiedad que beneficia a comunidades monásticas en detrimento de les comunidades de hombres libres. Esto sucede durante el proceso de consolidación de los grupos de poder feudal en formación y ya es bien visible en documentos de finales del siglo X. Obviamente la mayor parte de la documentación consultada procede de fondos monásticos por lo que los grupos de poder laico aparecen menos representados. A pesar de ello, no podemos olvidar que el hierro es el material empleado en la producción de armamento, por lo que podemos considerar la industria siderúrgica como una actividad estratégica desde el punto de vista militar y, por lo tanto, de gran interés para las élites militares del momento.

La importancia que adquieren los ejércitos de caballeros, perfectamente equipados, dentro del proceso de consolidación del sistema feudal, requiere de una industria siderúrgica capaz de producir cantidades importantes de hierro. El volumen de hierro que llevaba un caballero y su caballo o el que era necesario para la fabricación del equipamiento mínimo de una unidad familiar de producción campesina, debía superar los $20 \mathrm{Kg}$. que multiplicados por el número de caballeros y por el número de explotaciones agrarias, nos permite intuir hasta que punto era apreciado este metal ${ }^{55}$.

Ante esta realidad, no es de extrañar el interés de las élites por el control del proceso de producción de hierro, desde la industria pesada que produce el material de uso hasta la industria de transformación que le confiere el valor añadido del objeto listo para ser usado. El monopolio y el canon feudal (llòsol en tierras catalanas) se

mente aparece una cita más concreta en la donación que los condes de Pallars, Ramon y Ermesenda, realizan del honor de Fabregada a favor de Bertran Ató. En este documento se dan las afrontaciones que nos permitieron localizar dicho establecimiento. F. Miquel, Liber Feudorum, doc. 57.

53 Véase nota 46

${ }^{54}$ La excavación de la zona de trabajo de Fabregada se realizó entre los años 1992 y 1994, en un momento en que no era posible realizar análisis de radiocarbono sobre muestras de cenizas por no existir, en el ámbito arqueológico, la tecnología necesaria para llevarlos a cabo.

${ }^{55}$ A pesar de las diversas tipologías de cotas de malla, armaduras cascos o espadas, podemos indicar, a título orientativo, algunos pesos aproximados. Para una cota de malla sin mangas, unos 12 $\mathrm{Kg}$., la espada entre 2 y $3 \mathrm{Kg}$., el casco menos de $1 \mathrm{Kg}$., una armadura completa alrededor de $30 \mathrm{Kg}$. Respecto a los aperos de labranza, podemos encontrar rejas entre 3 y $10 \mathrm{Kg}$., hachas entre 1 y $5 \mathrm{Kg}$., azadones, hoces, palafangas y otras herramientas alrededor de 500 gr. 
establecen sobre el uso de los talleres de herrero, dado que es allí donde acuden los campesinos para reparar sus herramientas o fabricar de nuevas. La industria de transformación se especializa y pronto aparecerán diferenciados los simples herreros de los espaderos o cuchilleros que, incidirán en la reactivación del comercio tanto en el ámbito rural como en el urbano.

Mayor demanda de productos de calidad, mayor consumo, mayor actividad comercial que incidirá en una mayor exigencia de materia prima a la industria pesada, la cual ya no podrá hacer frente a la demanda desde las pequeñas fargas rurales propias de la Alta y la Plena Edad Media. La documentación es clara al respecto. Las fargas existentes hasta este momento irán desapareciendo y serán reemplazadas por otras situadas en las zonas más ricas en yacimientos de minerales de hierro, esto es en los valles altos del Pirineo. Las pequeñas fargas altomedievales habían perdido su razón de ser. Los talleres especializados se abastecerán de materia prima procedente de las nuevas fargas ubicadas en zonas mineras de mayor importancia donde, probablemente, a partir de finales del siglo XIII o inicios del XIV, se introducirá una importante mejora técnica en la industria pesada que permitirá aumentar la capacidad de los hornos de forma significativa. Nos referimos a la introducción de los fuelles hidráulicos, activados a partir de un árbol de levas primero y por un sistema bielamanivela algo más tarde.

Estas instalaciones llegarán a producir hornadas de más de $50 \mathrm{Kg}$. La producción ya no iría destinada a abastecer un consumo local sino que la producción se distribuiría por una red comercial, cada vez más compleja y más capaz de llegar hasta los grandes núcleos de consumo como son las ciudades en crecimiento. En la gestión de estas fargas participa, ya, el capital mercantil que busca personal cualificado tanto para la localización de minerales como para la producción de carbón y para el proceso de reducción. Si se considera necesario se contratan maestros fargaires del otro lado de los Pirineos y se establecen contratos de explotación en los que se prevé desde el abastecimiento de materias primas hasta la comercialización del producto final ${ }^{56}$.

Esta tecnología se perfeccionará y mantendrá en las conocidas Ferrerías Vascas hasta el siglo $\mathrm{XX}^{57}$, mientras que a partir del siglo XVI en la zona catalana, se introducirá la trompa de agua para insuflar aire en el horno, dando lugar a la internacionalmente conocida "farga catalana" 58 .

La documentación de los siglos XIV y XV, nos informa sobre las fargas de Ripoll, Ribes, Tuixent, Martinet o La Vansa, por citar algunas de ellas. En todos los casos las formas de explotación se alejan de los modelos feudales y se gestionan a partir de asociaciones de empresarios que controlan desde la extracción del mineral hasta la obtención del metal y su distribución. Los propietarios eminentes, reciben unas rentas anuales establecidas y definidas en los contratos de explotación. Las fargas como la de Fabregada empezaran a tener dificultades para localizar aquellos pequeños yacimientos de mineral que habían aportado la materia prima necesaria. Al mismo tiempo, aumentó la dificultad para encontrar bosques en donde hacer carbón, sin entrar en conflicto con otras comunidades del valle que también utilizaban este recurso forestal con otras finalidades. Por otro lado, la existencia de una red comercial ya estabilizada y generalizada, permitiría a los campesinos obtener las herramientas manufacturadas que antes sólo podían conseguir a través del autoabastecimiento.

La proliferación de estas industrias en los siglos siguientes, causará un impacto ambiental considerable, principalmente en los bosques que se explotaran inten-

56 J.M. Madurell, Las fargas pirenaicas.

${ }_{57}$ M. Urteaga, Ferrerías.

${ }^{58}$ E. Tomas, La Farga; P. Molera, Tècnica; P. Molera, C. Barrueco, Llibre. 
sivamente para producir el carbón que necesita esta industria ${ }^{59}$. Esto generará conflictos graves entre las comunidades que se verán privadas de un recurso indispensable para su economía, a pesar de que la deforestación favorecerá la creación de nuevas zonas de pasto.

El siguiente paso en la evolución técnica de les fargas será la introducción de la trompa de agua para la aireación forzada del horno. Como ya hemos indicado anteriormente, la aplicación de la trompa de agua completará el equipamiento de les fargas, dando lugar a la conocida farga catalana ${ }^{60}$. Con esta innovación se llegará al máximo desarrollo técnico de la siderurgia de horno bajo basada en el sistema directo para la obtención de hierro.

\section{A MODO DE CONCLUSIÓN}

El cambio que se produce en la transición al mundo medieval, provoca un proceso de ruralización de la sociedad que va acompañado del cierre de las grandes rutas comerciales y de la decadencia de los mercados urbanos. Podemos decir que la economía se atomiza, se vuelve más local y se vuelca al autoabastecimiento. El lujo deja paso a la necesidad y, a nivel metalúrgico, los metales preciosos dejan paso al hierro. Muchos historiadores han considerado estos cambios como un retroceso, para nosotros no es más que el paso de un sistema técnico a otro. El abandono de técnicas muy desarrolladas para la producción de objetos de lujo, deja paso a las innovaciones en la base productiva que se plasman en la generalización de la energía hidráulica y del hierro como material de uso. Las pequeñas comunidades rurales se convierten en agentes activos del cambio tecnológico al disponer de un control considerable sobre las estrategias de producción, disponibilidad de mano de obra, capacidad técnica, conocimiento del medio y motivación para su propio abastecimiento.

Este cambio de sistema técnico conlleva unas nuevas formas de explotación de los recursos y establece unas nuevas relaciones entre los colectivos humanos y el entorno. Como consecuencia de todo ello el paisaje se transforma: el hábitat cambia de lugar, las vías de comunicación responden a la voluntad de acceder a zonas hasta el momento inéditas, los bosques se antropizan, las pequeñas zonas de extracción de minerales proliferan, los cultivos ocupan nuevas parcelas, las laderas se aterrazan y los cursos de agua se domestican. Este modelo irá evolucionando sobre las mismas bases técnicas hasta la irrupción de la mecanización, paralela a la industrialización y acompañada de la introducción de nuevas energías y nuevos materiales, propiciando un profundo cambio capaz de transformar, de nuevo, el paisaje rural.

Respecto a la producción siderúrgica y como resultado de los estudios que hemos realizado en la zona de Pirineo y Prepirineo catalán, percibimos una evolución que podemos resumir en tres puntos para la Edad Media, más uno que nos lleva hasta principios del siglo XX.

En una primera fase que llega hasta el siglo IX, encontramos hornos bajos de reducción itinerantes, situados a pié de mina y cercanos a los bosques donde se produce el carbón vegetal necesario para el proceso de reducción. Estos hornos disponen de tiro forzado manual, canal y pozo para la evacuación de las escorias. En estas instalaciones, el proceso de primer forjado del hierro recién sacado del horno se realizaba manualmente. La capacidad de producción de dichos hornos, para cada hornada, se

\footnotetext{
${ }^{59}$ S. Riera, A. Esteban, Vegetation, pp. 7-23.

${ }^{60}$ P. Molera, Tècnica, pp. 33-44.
} 
situaría entre 5 y $10 \mathrm{Kg}$. A menudo se encuentran dispuestos en batería siendo habitual la localización de un número elevado de hornos agrupados en un mismo lugar.

Un segundo período que podemos situar entre los siglo IX-XIII, se caracterizaría por la presencia de hornos de reducción estables, situados al lado de cursos de agua y no muy alejados de los yacimientos de óxidos de hierro y de una masa forestal susceptible de ser convertida en carbón. Los hornos continúan siendo bajos, con tiro forzado manual, canal y pozo para la evacuación de las escorias. La primera forja se realizaría con mazo hidráulico, lo que justificaría su ubicación al lado de una corriente de agua. Este cambio posibilitaría aumentar la capacidad del horno que llegaría a una producción por hornada situada alrededor de los 25-30 Kg. Estas instalaciones se convirtieron en un elemento singular y fueron utilizadas para definir la ubicación de otros elementos del paisaje o los límites de las circunscripciones territoriales.

Ya en los siglos XIV-XV, asistimos a otro cambio significativo. Los hornos de reducción continúan siendo estables y se encuentran situados al lado de cursos de agua. La gran diferencia de su ubicación radica en que ya no los encontramos en zonas donde el volumen de minerales de hierro aptos para su reducción es limitado, sino que se acercan a los grandes yacimientos de óxidos de hierro y a las grandes masas forestales, que en nuestro caso se encuentran en los valles pirenaicos. Los hornos continúan siendo bajos pero con tiro forzado mediante fuelles hidráulicos, mientras que para la primera forja se sigue utilizando el mazo hidráulico. El tiro forzado del horno supondrá un nuevo incremento de la capacidad de producción por hornada que deberemos situar por encima de los $50 \mathrm{Kg}$.

Finalmente, ya en los siglos XVI-XX, podemos hablar de las instalaciones siderúrgicas conocidas como fargas catalanas y que se caracterizan por disponer de un sistema de aire forzado mediante la trompa de agua. Su paralelo en las zona de influencia vasca, serían las ferrerías vascas, dotadas de un sistema de fuelles hidráulicos para insuflar aire al interior del horno. Las demás características se mantienen respecto la fase anterior pero asistimos a un nuevo incremento de la productividad por hornada que se situaría por encima de los $100 \mathrm{Kg}$.

La evolución de la técnica siderúrgica continuará con la irrupción de los altos hornos, algunos de ellos ya en el siglo XIV, que aplicarán el sistema indirecto para la obtención de hierro. A pesar de las dificultades, las fargas catalanas y las ferrerías vascas competirán con los altos hornos hasta finales del siglo XIX e incluso hasta principios del siglo XX, momento en que la falta de combustible y la imposibilidad de utilizar carbón mineral, como sí utilizan los altos hornos, comportará el cierre definitivo de los últimos establecimientos de estas características. 


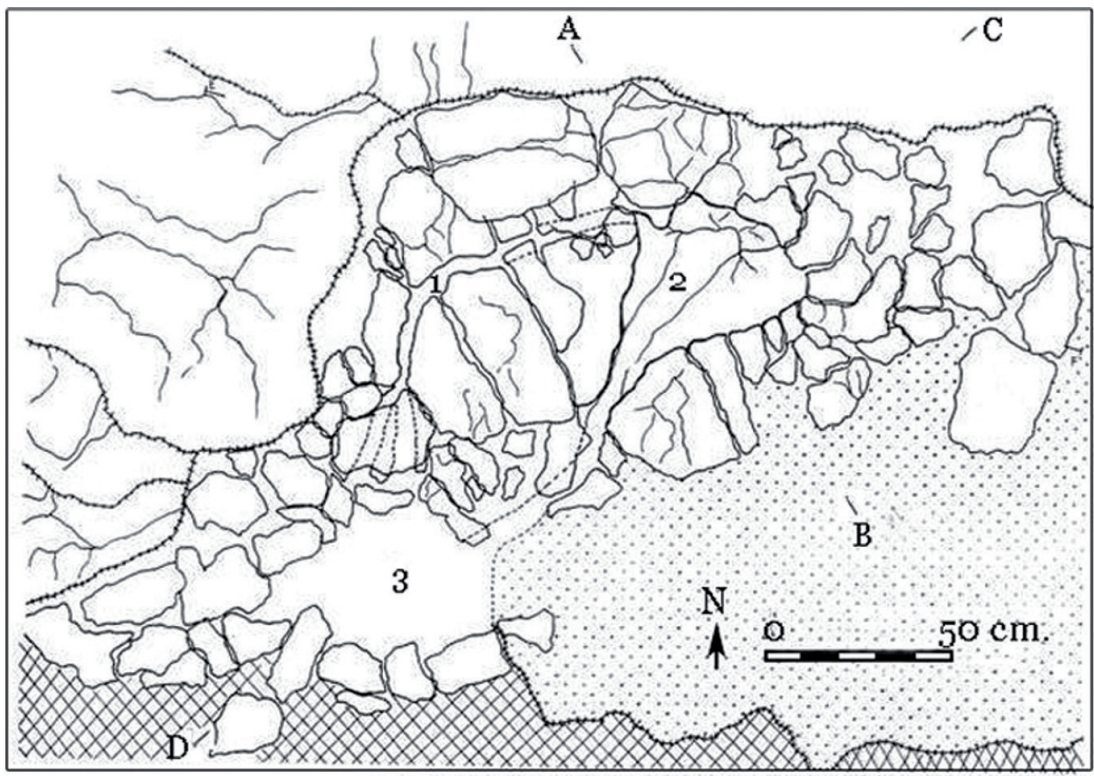

Fig. 1. Planta de las estructuras del horno de Fabregada. 1: Canal de aireación forzada del horno. 2: Cámara de reducción. 3: Pozo de escorias. Las letras corresponden a los ejes de las secciones (figuras 2 y 3 ). La trama punteada corresponde al nivel de circulación de coloración rojiza. La trama de líneas entrecruzadas corresponde al nivel de circulación de coloración gris-negra (dibujo de M. Sancho).

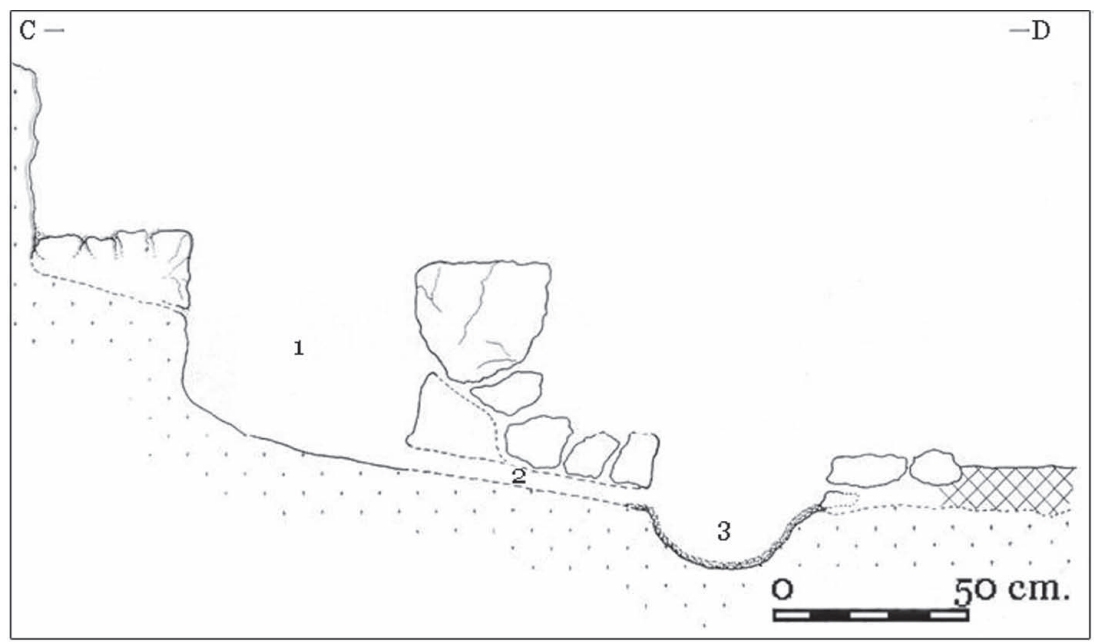

Fig. 2. Sección por C-D de las estructuras del horno de Fabregada. 1: Cámara de reducción. 2: Canal de evacuación de escorias. 3: Pozo de escorias. En el extremo derecho con trama de líneas entrecruzadas, se aprecia el nivel de circulación de coloración gris-negra (dibujo de M. Sancho). 


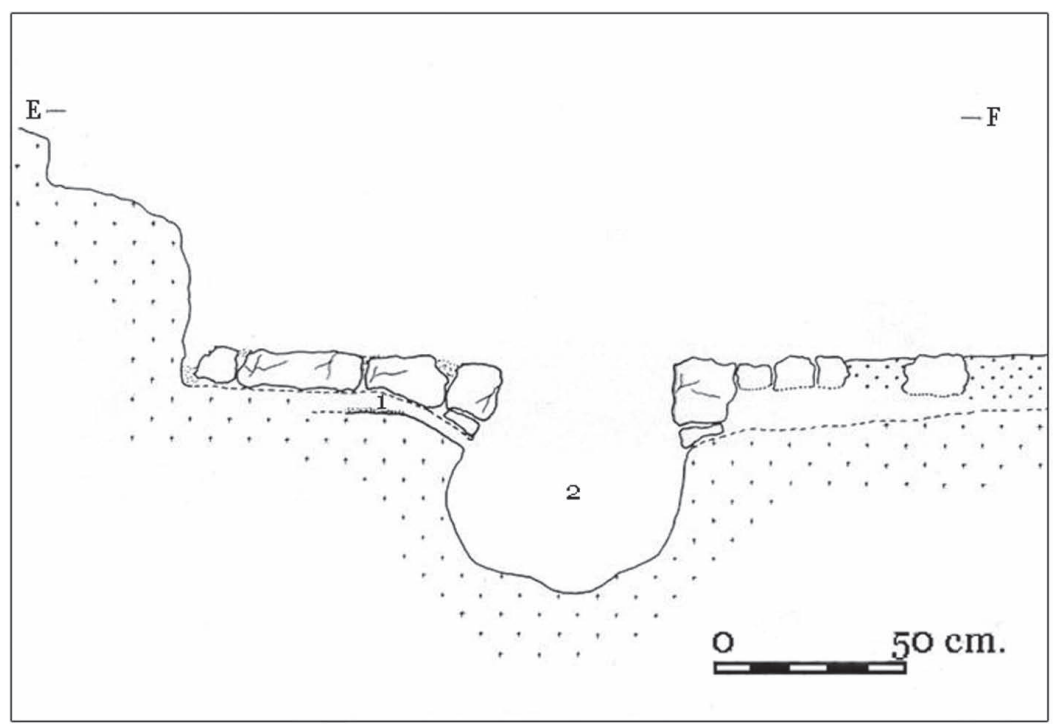

Fig. 3. Sección por A-B de las estructuras del horno de Fabregada. 1: Entrada inclinada del canal de aireación forzada del horno. 2: Cámara de reducción en la que se aprecia el inicio del canal de evacuación de escorias. A la derecha. Con trama punteada se observa el nivel de circulación de coloración rojiza (dibujo de M. Sancho).

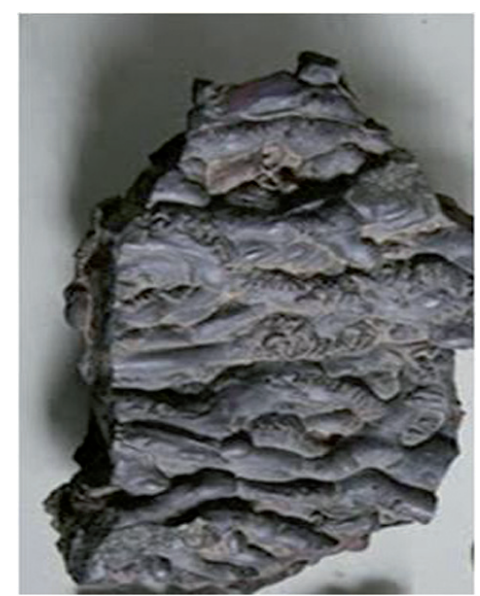

Fig. 4. Imagen de la escoria de mayor tamaño encontrada en la zona del escorial de Fabregada. Sus dimensiones aproximadas son $30 \times 25 \times 10 \mathrm{~cm}$. y tiene un peso de 7'850 Kg. En la superficie se observan los cordones escorificados propios de las escorias licuadas que salen de los hornos de reducción (fotografía de M. Sancho). 


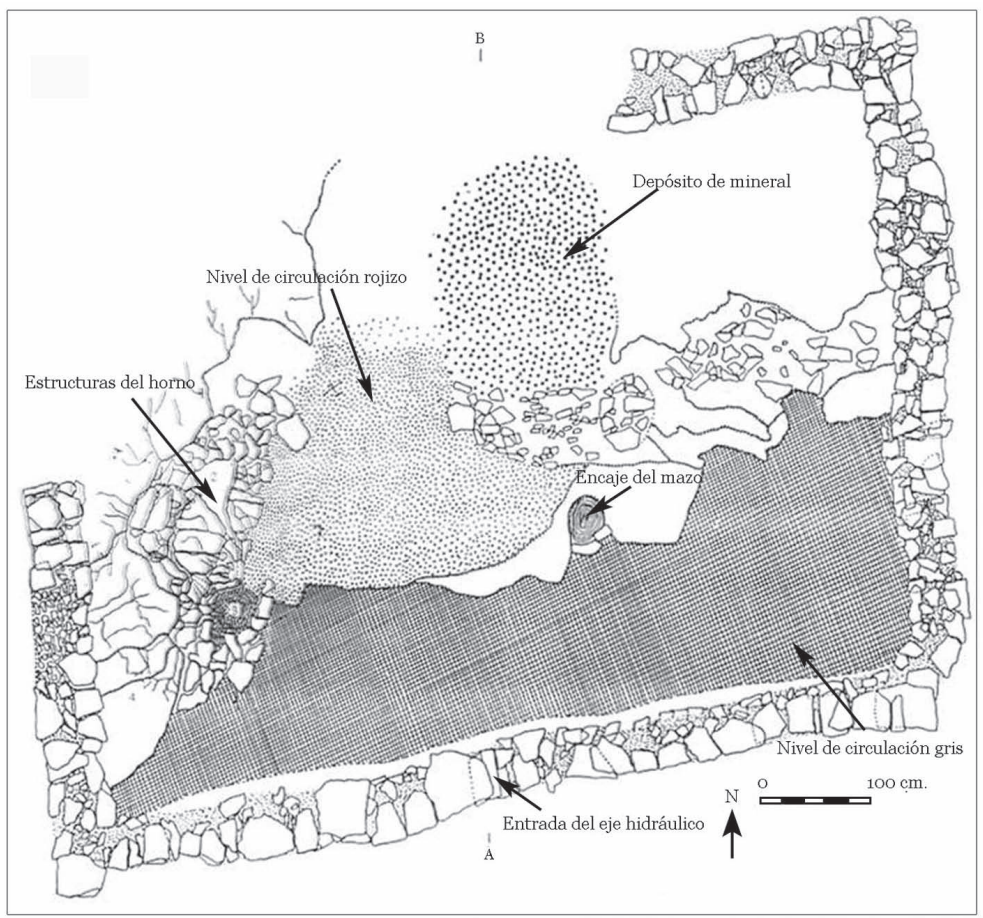

Fig. 5. Planta general de la farga de Fabregada en la que se observa la distribución del espacio y los distintos elementos identificados (dibujo de M. Sancho).

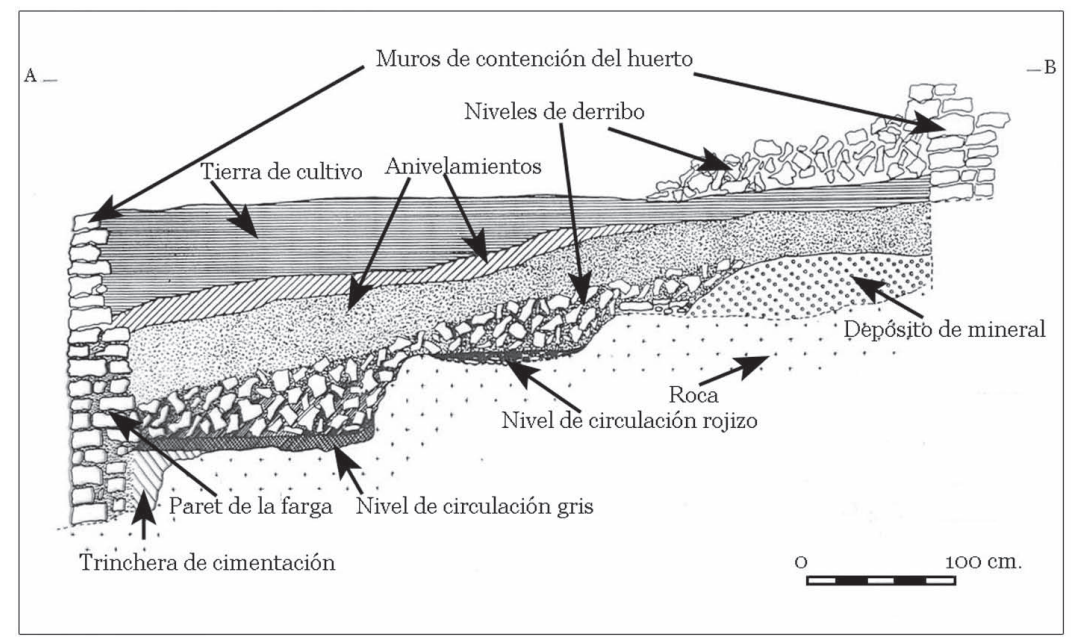

Fig. 6. Sección general de la farga de Fabregada por A-B. Se observa la organización en terrazas y los distintos niveles arqueológicos identificados (dibujo de M. Sancho). 


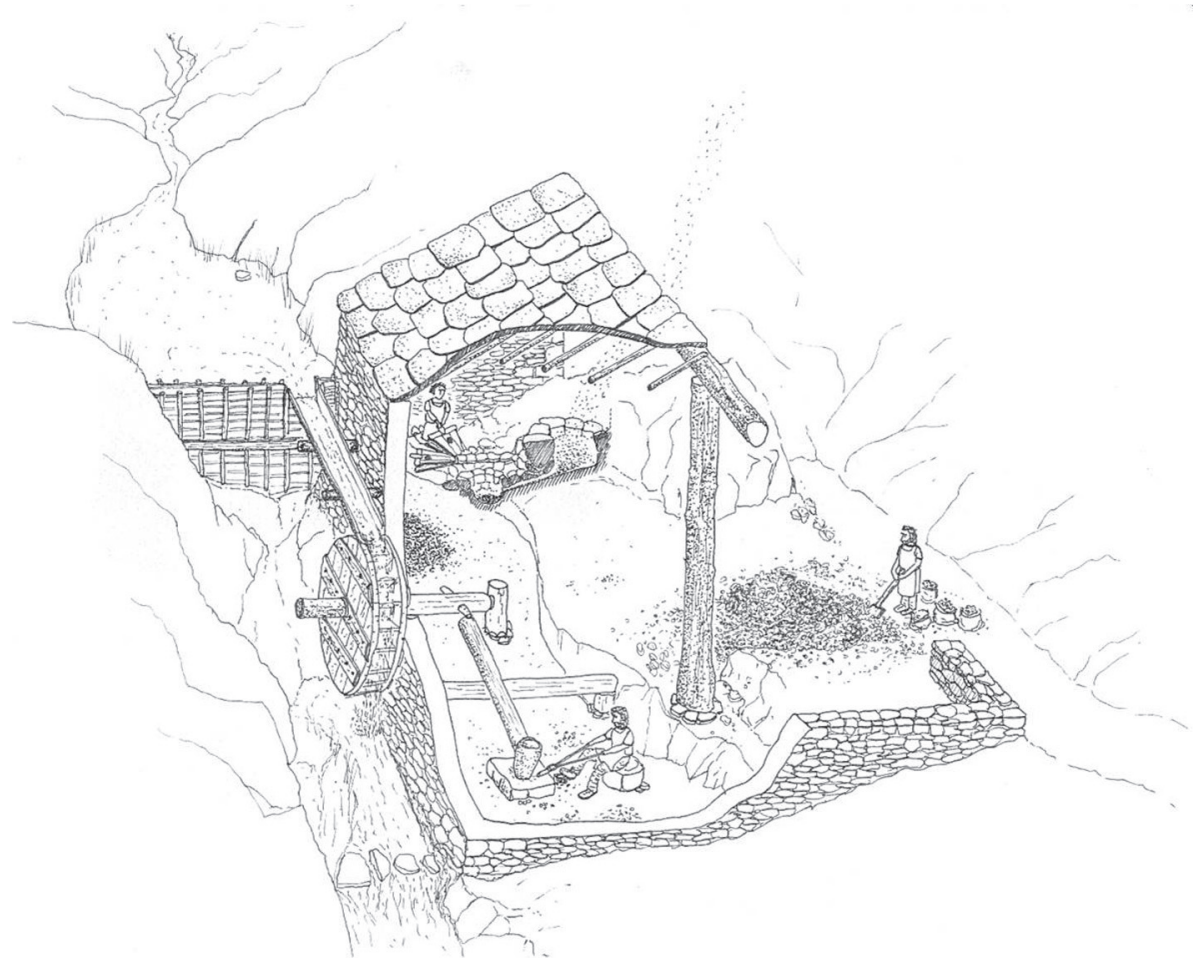

Fig. 7. Reconstrucción ideal de la farga de Fabregada a partir de las plantas y secciones realizadas durante la intervención. Se observan las estructuras del horno con el sistema de aireación, la cámara de reducción y el pozo de escorias; los depósitos de mineral, a la derecha y de carbón, delante del horno; el sistema del mazo hidráulico y las infraestructuras de almacenamiento y conducción del agua (dibujo de Ferran Compte y Marta Sancho).

\section{BIBLIOGRAFÍA CITADA}

Amblas, Oriol; Molera, Judit; Ollich, Imma, Estudio arqueometalúrgico: La herrería medieval de l'Esquerda, siglos XII-XIII dc (Roda de Ter, Catalunya), en VI Congreso Ibérico de Arqueometría, Madrid, 2008, pp. 500-509.

http://humanidades.cchs.csic.es/ih/congreso_iberico/42.PDF [consulta: 19/07/2011].

Benoit, Fernand, L'usine de meunerie hydraulique de Barbegal (Arles), "Revue Archéologique" 15/1 (1940).

Benoit, Paul; Cailleaux, Denis (eds.), Moines et métallurgie dans la France Médiévale, París, 1991.

Beyrie, Argitxu; Kammenthaler, Eric, Aux origines de l' activité minière dans les Pyrénées occidentales. L' exploitation du cuivre, du fer, de l'or et de l'argent, "Archéopages" 22 (2008), pp. 28-33.

Beyrie, Argitxu; Kammenthaler, Eric, Inventaire des sites miniers et métallurgiques en vallée d'Ossau (Pyrénées-Atlantiques), en $5^{e}$ Journée - Mines, métallurgie, artisanat du métal: nouvelles données, Toulouse, 2006. 
Beyrie, Argitxu; Kammenthaler, Eric, Le centre sidérurgique antique de Larla, "Bilan scientifique 2003” (2004), pp. 162-164.

Bolòs, Jordi, Els orígens medievals del paisatge català. L'arqueologia del paisatge com a font per a conèixer la història de Catalunya, Barcelona, 2004.

Bosch, Josep M.; Mestres, Josep; Molist, Núria; Senabre, Maria Rosa; Socias, Joan, Olèrdola. El procés d'urbanització feudal: un possible exemple de continuïtat d'un lloc antic (segles VIII-X), en Catalunya a l'època carolíngia. Art i cultura abans del romànic (segles IX-X), Barcelona, 2000, pp. 95-99.

Boserup, Esther, Las condiciones del desarrollo en la agricultura, Madrid, 1967.

Boserup, Esther, Población y cambio tecnológico, Barcelona, 1984.

Campmajo, Pierre; Crabol, Denis; Bille, Elisabeth; Raynaud, Claude; Ruas, MariePierre; Parent, Gilles; Rendu, Christine, Un atelier de traitement du fer sur le site du haut Moyen âge de la Coume Païrounell à Angoustrine (PyrénéesOrientales). Premiers résultats, "Domitia" 8-9 (2007), pp. 133-167.

Canto, Alberto; Cressier, Patrice (eds.), Minas y metalurgia en al-Andalus y Magreb occidental: Explotación y poblamiento, Madrid, Casa de Velázquez, 2008.

D’Abadal, Ramon, Catalunya Carolíngia III. Els comtats de Pallars i Ribagorça, 2 vols., Barcelona, 1955.

Coromines, Joan, Diccionari etimològic i complementari de la llengua catalana, Barcelona, 1980-1991.

Decombeix, Pierre-Michel; Domergue, Claude; Fabre, Jean-Marie; Gorgues, Alexis; Rico, Christian; Tollon, Francis; Tournier, Benjamin, Réflexions sur l'organisation de la production du fer à l'époque romaine dans le bassin supérieur de la Dure, au voisinage Des Martys (Aude), "Gallia" 57 (2000), pp. 23-36.

Domergue, Claude, Les Martys. Domaines des Forges, Archéologie de la France: http://www.adlfi.fr/SiteAdfi/document?base=base_notices\&id=N2004-LA0132\#haut_000000037 [consulta: 19/07/2011].

Domergue, Claude (dir.), Un centre sidérurgique romain de la Montagne Noire. Le domaine des forges (Les Martys, Aude), París, 1993.

Dubois, Claude; Metailie, Jean-Pierre; Izard, Véronique, Archéologie de la forêt charbonnée: questions et méthodes, illustrées par l'exemple du site de Lercoul (Ariège), Antibes, 1997, pp. 525-540.

Farias, Víctor, Les ferreries al nord-est de la Catalunya Vella (segles XI-XIV). Una contribució a l'estudi d'una institució senyorial en L'obtenció del ferro pel procediment directe entre els segles IV $i$ XIX, Andorra la Vella, 2001.

Gibert, Jordi, L'Alta Edat Mitjana a la Catalunya central (segles VI-XI). Estudi històric $i$ arqueològic de la conca mitjana del riu Llobregat, Barcelona, 2011. https://www.educacion.gob.es/teseo/imprimirFicheroTesis.do?fichero= 25369 [consulta: 19/07/2011].

Glacken, Clarence J., Huellas en la playa de Rodas. Naturaleza y cultura en el pensamiento occidental desde la Antigüedad hasta finales del siglo XVIII, Barcelona, 1996.

Leveau, Philippe, The Barbegal water-mill in its environment: Archaeology and the economic and social history of Antiquity, "Journal of Roman Archaeology" 9 (1996).

Llinàs, Joan; Merino, Jordi; Miró, Manel; Montalban, Carme; Palahí, Lluís; Sagrera, Jordi, Excavacions d'urgència a la plaça Ramon Muntaner (Perelada, Alt Empordà), en Segones jornades d'arqueologia de les comarques de Girona, Torroella de Montgrí, 1994, pp. 147-155.

Madurell, Josep M., Las fargas pirenáicas (notas para su historia), "Pirineos" 25 (1952). 
Mangin, Michel; Fluzin, Philippe, La petite sidérurgie en contexte rural: les forges du Haut-Auxois mandubien et de ses marges lingonnes (Côte-d'Or), "Revue archéologique de Picardie" 1-2 (2003), pp. 141-156.

Martín, Carlos, El oro en Las Médulas: su geología y arqueología, Madrid, 2006.

Mata, Josep M., Els minerals de Catalunya, Barcelona, 1990.

Mathieu, Jon; Boserup, Ester, Naturaleza y cultura en los procesos de desarrollo, "Población \& Sociedad" 17 (2010), p. 40

Miquel, Francesc, Liber Feudorum Maior. Cartulario que se conserva en el ACA, Barcelona, 1945.

Molera, Pere, Tècnica de la farga, en S. Riera (ed.), La Farga Catalana: Un procés siderúrgic autòcton, Barcelona, 1997, pp. 33-44.

Molera, Pere; Barrueco, Consol, Llibre de la Farga, Barcelona, 1983.

Orengo, Héctor, Arqueología de un paisaje cultural de alta montaña. Dinámicas de ocupación del valle del Madriu-Perafita-Claror (Andorra), tesis doctoral presentada en el Institut Català d'Arqueologia Clàssica, Barcelona, 2010.

Padilla, José Ignacio, Aportación al estudio de la estructura económica de un monasterio altomedieval. Un prototipo: Sant Pere de Garu d'Escales, “Acta Historica et Archaeologica Mediaevalia" 1 (1980), pp. 197-224.

Pages, Gaspard, La métallurgie du fer en France méditerranéenne de l'Antiquité au début du Moyen Âge : jalons d'une approche interdisciplinaire, Montpellier, 2009. (http://hal.archives-ouvertes.fr/docs/00/35/73/91/PDF/I_Texte.pdf)

Puig, Ignasi, El Monestir de Santa Maria de Gerri : segles XI-XV, Barcelona, 1991.

Raurich, Xim; Mestre, Anna, L'excavació del barri de Mataplana, en M. Riu (dir.), El Castell de Mataplana. L'evolució d'una fortificació senyorial (s.XI-XV), Barcelona, 1994.

http://books.google.es/books?id=1dcKmq6DGVUC\&pg=PA7\&lpg=PA7\& $\mathrm{dq}=\mathrm{El}+$ Castell+de+Mataplana. $+\mathrm{L} \% 27$ evoluci\%C3\%B3+d\%27una+fortifi caci $\% \mathrm{C} 3 \% \mathrm{~B} 3+$ senyorial\&source=bl\&ots=w8E0RoW60I\&sig=ZomlWxy SGBkBQGrZN113tooP2LE\&hl=ca\&ei=x7AlToTfG4yUOpScrbkK\&sa=X \&oi=book_result\&ct=result\&resnum $=2 \&$ sqi $=2 \& v e d=0 C B 0 Q 6 A E w A Q \# v$ $=$ onepage $\& \mathrm{q} \& \mathrm{f}=$ false [consulta: 19/07/2011].

Rico, Christian; Fabre, Jean-Marc; Polo Cutando, Clemente; Villagordo, Carolina, Recherches sur la sidérurgie ancienne dans la Sierra Menera (Teruel-Guadalajara). Bilan des travaux des années 2003-2004, "Mélanges de la Casa de Velázquez" 35/2 (2005), Lire les territoires des sociétés anciennes, pp. 345-353.

Riera, Santi; Esteban, Agustí, Vegetation History and Human Activity During the Last 6.000 Years on the Central Catalan Coast (Nortestern Iberian Peninsula, "Vegetation History and Archeobotany" 3/1 (1994), pp. 7-23.

Rius, José, Cartulario de St. Cugat del Vallés, 3 vols., Barcelona, 1945-1947.

Rovira, M. Carmen; Solans, Joaquim, Les activitats metal-lúrgiques, en Roc d'Enclar. Transformacions d'un espai dominant (segles IV-XIX), Andorra la Vella, 1997, pp. 351-365.

Sancho, Marta, Ipsa Fabricata. Estudio arqueológico de un establecimiento siderúrgico medieval, Barcelona, 1997.

http://books.google.com/books/about/Ipsa_Fabricata_Estudi_arqueol \%C3\%B2gic_d_un.html?hl=es\&id=AubJ6j1C8RMC [consulta: 19/07/2011].

Sancho, Marta, Aguas, rocas y metales: Arqueología y explotación de recursos minerales en la Edad Media, "Acta Historica et Archaeologica Mediaevalia" 29 (2009).

Sancho, Marta, Homes, fargues, ferro i foc. Arqueologia i documentació per a l'estudi de la producció de ferro en època medieval, Barcelona, 1999. 
http://books.google.com/books?id=W8z_ftcLmhEC\&printsec=frontcover $\& \mathrm{dq}=$ homes,+ fargues,+ ferro $+\mathrm{i}+$ foc $\&$ hl $=$ es $\&$ ei $=$ n7IlTr7sOYSz8QPnicX3C $\mathrm{g} \& \mathrm{sa}=\mathrm{X} \&$ oi=book_result\&ct=result\&resnum $=1 \& \mathrm{ved}=0 \mathrm{CDAQ6AEwAA \#}$ $\mathrm{v}=$ onepage \&q\&f=false [consulta: 19/07/2011].

Sancho, Marta, Patrones de asentamiento, ocupación del territorio y explotación de recursos en áreas de montaña (siglos VI-XI), en J.F. Utrilla; G. Navarro (eds.), Espacios de montaña: Las relaciones transpirenaicas en la Edad Media, Zaragoza, 2010.

Sellin, Robert H.J., The large roman water mill at Barbegal (France), "History of Technology" 8 (1983).

Simon, Julia, Testimonios de una actividad metalúrgica en el yacimiento de Fabregada, en M. Sancho (dir.), Ipsa Fabricata. Estudio arqueológico de un establecimiento siderúrgico medieval, Barcelona, 1997, pp. 107-129

Tomas, Estanislau (coord.), La Farga Catalana en el marc de l'arqueologia siderúrgica, Andorra la Vella, 1995.

Tura, Jordi; Amblas, Oriol, El material metàl-lic del Castell de Montsoriu. Segles XIXIX (Arbúcies - Sant Feliu de Buxalleu, La Selva), en O. Amblas; M. Ocaña (coords.), Seminari eines $i$ instrumental metàl-lic medieval (s. V-XV), Roda de Ter, 2002, pp. 58-65.

Urteaga, Mercedes, Ferrerías hidráulicas en Guipúzcoa, en E. Tomás (coord.), La Farga Catalana en el marc de l'arqueologia siderúrgica, Andorra la Vella, 1995.

Verna, Catherine, Le temps des moulines: Fer, technique et société dans les Pyrénées centrales, XIIIè-XVIè siècles, París, 2001.

http://books.google.es/books?id=zpgWNOOHBhAC\&dq=catherine+Verna +sancho+fabregada\&hl=ca\&source=gbs_navlinks_s [consulta: 19/07/2011].

Verna, Catherine, Réduction du fer et innovation: À propos de quelques débats en histoire sociale des techniques, «Médiévales» 39 (2000), pp. 79-95.

http://www.persee.fr/web/revues/home/prescript/article/medi_0751-2708_

2000_num_19_39_1495?_Prescripts_Search_tabs $1=$ standard $\&[$ consulta: 19/07/2011].

Vila, Josep M., Excavació arqueològica a l'església de Sant Joan del Pla (La Palma, Baix Llobregat), en II Congrés d'Arqueologia Medieval i Moderna de Catalunya, Sant Cugat del Vallès, 2003, pp. 536-544.

White, Lynn T., Tecnología medieval y cambio social, Buenos Aires, 1973.

Wickham, Christopher, Una Historia Nueva de La Alta Edad Media, Barcelona, 2009.

Fecha de recepción del artículo: julio 2011

Fecha de aceptación y versión final: octubre 2011 